\title{
A New Classification System for IgG4 Autoantibodies
}

Inga Koneczny*

Institute of Neurology, Medical University of Vienna, Vienna, Austria

IgG4 autoimmune diseases are characterized by the presence of antigen-specific autoantibodies of the lgG4 subclass and contain well-characterized diseases such as muscle-specific kinase myasthenia gravis, pemphigus, and thrombotic thrombocytopenic purpura. In recent years, several new diseases were identified, and by now 14 antigens targeted by IgG4 autoantibodies have been described. The IgG4 subclass is considered immunologically inert and functionally monovalent due to structural differences compared to other lgG subclasses. IgG4 usually arises after chronic exposure to antigen and competes with other antibody species, thus "blocking" their pathogenic effector mechanisms. Accordingly, in the context of lgG4 autoimmunity, the pathogenicity of lgG4 is associated with blocking of enzymatic activity or protein-protein interactions of the target antigen. Pathogenicity of IgG4 autoantibodies has not yet been systematically analyzed in lgG4 autoimmune diseases. Here, we establish a modified classification system based on Witebsky's postulates to determine IgG4 pathogenicity in IgG4 autoimmune diseases, review characteristics and pathogenic mechanisms of lgG4 in these disorders, and also investigate the contribution

OPEN ACCESS

Edited by: Ralf J. Ludwig, University of Lübeck, Germany

Reviewed by: Jun-ichi Kira, Kyushu University, Japan Lars Komorowski, Institute of Experimental Immunology Affiliated to Euroimmun AG, Germany

*Correspondence: Inga Koneczny inga.koneczny@gmail.com

Specialty section: This article was submitted to Immunological Tolerance and Regulation, a section of the journal

Frontiers in Immunology

Received: 16 November 2017 Accepted: 12 January 2018 Published: 12 February 2018

Citation: Koneczny I (2018) A New Classification System for IgG4 Autoantibodies.. Front. Immunol. 9:97. doi: 10.3389/fimmu.2018.00097 of other antibody entities to pathophysiology by additional mechanisms. As a result, three classes of lgG4 autoimmune diseases emerge: class I where lgG4 pathogenicity is validated by the use of subclass-specific autoantibodies in animal models and/or in vitro models of pathogenicity; class II where lgG4 pathogenicity is highly suspected but lack validation by the use of subclass specific antibodies in in vitro models of pathogenicity or animal models; and class III with insufficient data or a pathogenic mechanism associated with multivalent antigen binding. Five out of the $14 \mathrm{lgG} 4$ antigens were validated as class I, five as class II, and four as class III. Antibodies of other IgG subclasses or immunoglobulin classes were present in several diseases and could contribute additional pathogenic mechanisms.

Keywords: IgG4 autoimmunity, IgG4, autoimmunity, neuronal autoantibodies, muscle-specific kinase myasthenia gravis, thrombotic thrombocytopenic purpura, pemphigus, IgG4-related disease

\section{INTRODUCTION}

Autoantibodies are key pathogenic players in a wide range of autoimmune diseases. Immunoglobulins (Ig) of IgG or IgM class that bind either to cell surface-expressed or extracellular matrix antigens induce organ-specific damage in type II hypersensitivity diseases. More systemic autoimmune diseases are classified as type III hypersensitivity diseases and are characterized by circulating IgG and

Abbreviations: ADAMTS13, disintegrin and metalloproteinase with thrombospondin motifs 13; CIDP, chronic inflammatory demyelinating polyneuropathy; CNTN1, contactin 1; Caspr1,2, contactin associated protein 1,2; Dsg1,3, desmoglein 1, 3; DPPX, dipeptidyl peptidase-like protein 6; FAE, Fab-arm exchange; GSH, glutathione; Iglon5, IgLON family member 5; Lgil, leucine-rich, glioma-inactivated 1; Lrp4, low-density lipoprotein receptor-related protein 4; MBL, mannose-binding lectin; MuSK, muscle-specific kinase; MG, myasthenia gravis; PLA2R, phospholipase A2 receptor; THSD7A, thrombospondin type-1 domain-containing 7A; TTP, thrombotic thrombocytopenic purpura; vWF, von Willebrand factor. 
IgM as well as IgA that binds soluble antigen and forms immune complexes. Antibody-mediated autoimmune diseases include many different pathogenic mechanisms [reviewed in detail by Ref. (1)]. Among these are complement activation, recruitment of immune cells via Fc receptors (leading to antibody-dependent cellular cytotoxicity, opsonization, phagocytosis, and overall immune-mediated damage and inflammation), cross-linking of antigen that leads to immune complex formation or endocytosis of transmembrane antigen, or the direct modulation of antigen function. With the exception of the latter, these mechanisms rely on antibody class and subclass, particularly on the sequence and structure of the constant regions. Single amino acids in the constant region of IgG4 are responsible for structural differences that render it unable to exert most of the known pathogenic functions of antibodies. Despite their immunological inertness, several well-described autoimmune diseases are caused by IgG4 subclass autoantibodies, such as pemphigus, muscle-specific kinase (MuSK) myasthenia gravis (MG), and thrombotic thrombocytopenic purpura (TTP), and in recent years the number of potential IgG4 autoimmune diseases has rapidly grown. By now, 14 autoantigens are known that are targeted by IgG4 subclass autoantibodies; these antigens are found throughout the body (Table 1), with more than half being located in the central and peripheral nervous system. Whether all of the newly described IgG4 autoantibodies are pathogenic at all, if so by what mechanism, and if they are the sole pathogenic entity in their disease are essential questions that have been addressed to variable extent in the different fields. Here, we review what is known about IgG4 autoantibodies within the scope of IgG4 autoimmunity and attempt to analyze and classify proposed IgG4 autoimmune diseases based on a set of modified Witebsky postulates to validate IgG4 pathogenicity.

\section{IgG4: FROM STRUCTURE TO FUNCTION}

\section{IgG4 Structure}

IgG is the predominant antibody class and one of the most abundant glycoproteins in the human plasma with concentrations of approximately 7-15 g/L. In humans, four subclasses are known, IgG1, 2, 3 and 4, which are named in descending order of frequency (136). IgG4 is the least common IgG subclass, comprising only $5 \%$ of total $\operatorname{IgG}(137,138)$. It is important to keep in mind that there is a different distribution in mice which are often used as animal models for pathogenicity, here the IgG1 subclass is the non-complement fixing subclass equivalent to $\mathrm{IgG} 4$, and in addition there are complement fixing IgG2a, IgG2b, and IgG3 subclasses (139-141). Also, there is different capability of human IgG to bind to rodent complement or Fc receptors, which needs to be considered in passive transfer models, e.g., by additional transfer of human complement (142).

The four human IgG subclasses share a similar structure with over $90 \%$ sequence homology. IgGs are heterotetramers, consisting of two heavy $(50 \mathrm{kDa})$ and two light chains $(25 \mathrm{kDa})$ of either $\kappa$ or $\lambda$ type. The heavy chain consists of three constant domains
$\left(\mathrm{C}_{\mathrm{H}}\right)$ that mediate the antibody effector functions, a hinge region between $\mathrm{C}_{\mathrm{H}} 1$ and $\mathrm{C}_{\mathrm{H}} 2$, and one $\mathrm{N}$-terminal variable domain $\left(\mathrm{V}_{\mathrm{H}}\right)$, which recognizes antigen. Similarly, the light chain is comprised of one variable $\left(\mathrm{V}_{\mathrm{L}}\right)$ antigen binding and one constant $\left(\mathrm{C}_{\mathrm{L}}\right)$ region. The $\mathrm{V}_{\mathrm{H}}$ contains three complementarity-determining regions (CDR 1-3). These three CDRs, and particularly the CDR3, are hypervariable to allow for improved and highly specific binding of antigen. Increased mutation rates at this genetic locus indicate antigen-driven somatic mutations.

Disulfide bridges connect the light and heavy chains to form half-antibodies (HL), and two HL are joined together by covalent and non-covalent interactions between the heavy chains to form a whole antibody $\left(\mathrm{H}_{2} \mathrm{~L}_{2}\right)$. The heavy chains are mainly connected by disulfide bridges in the hinge region, which vary in numbers between the IgG subclasses. IgG1 and IgG4 have two disulfide bridges in the hinge region, while IgG2 has four and IgG3 11 (143-145). The disulfide bonds that connect heavy and light chains also vary between subclasses, in IgG1 they connect the n-term of the $\mathrm{C}_{\mathrm{L}}$ domain with the $\mathrm{c}$-term of the $\mathrm{C}_{\mathrm{H}} 1$ domain, while in IgG2-4 the c-term of the $\mathrm{C}_{\mathrm{L}}$ domain is connected to the n-term of the $\mathrm{C}_{\mathrm{H}} 1$ region.

Upon enzymatic digestion with papain, antibodies are divided into three fragments, one Fc fragment ("Fragment crystallized"), consisting of the $\mathrm{C}_{\mathrm{H}} 2-\mathrm{C}_{\mathrm{H}} 3$ of both heavy chains including the hinge, and two Fab fragments ("Fragment, antigen binding"), consisting of the $\mathrm{C}_{\mathrm{H}} 1, \mathrm{~V}_{\mathrm{H}}, \mathrm{C}_{\mathrm{L}}$, and $\mathrm{V}_{\mathrm{L}}$. The corresponding regions in the intact antibody are thus named "Fab" or "FC" region [Figure 1A, reviewed by Ref. (146)]. Particularly interesting in IgG4 is the hinge and Fc region; while there is a high degree of homology between the IgG subclasses, there are single amino acid differences that have immediate consequences for IgG4 structure and effector function.

\section{Functional Characteristics of IgG4: Immunological Inertness and Fab-Arm Exchange (FAE)}

Single amino acid changes in the $\mathrm{C}_{\mathrm{H}} 2$ region (exchange of a proline for a serine at position 331, "P331S") prevent binding of the protein $\mathrm{Clq}(148,149)$, the initial binding molecule of the classic complement cascade, and together with further changes (single amino acid replacements of L234F, P331S, and A327G) also cause a reduced binding to activating Fc $\gamma$ receptors, but not to the inhibitory FcyRIIb (150-155). The exchange of a proline for a serine in the IgG4 hinge region at position 228 compared to IgG1 (P228S) leads to greater stereometric flexibility. This flexibility allows disulfide bridges in the hinge to additionally form within the same heavy chain ("intra-chain" disulfide bonds) instead connecting the two heavy chains ("inter-chain" disulfide bonds). Under reducing conditions, these states are dynamic and in equilibrium [Figure 1A (156-158)]. Together with reduced non-covalent interactions between the heavy chains in the $\mathrm{C}_{\mathrm{H}} 3$ region caused by an arginine instead of lysine (R409K) $(159,160)$, the two HL can dissociate (161-163) and recombine with other HL, in a process termed FAE [Figure 1B (161, 164-166)]. The resulting antibodies are bispecific and can cross-link two different 
TABLE 1 | Classification of IgG4 autoimmune diseases

Antigen Epitope

Other Antibody binding Pathogenic mechanism of

Active immunization Biopsy/imaging

Other pathogenic

References

antibodies to affected organ lgG4

or passiv

finding

mechanis

\section{Class I disease}

MuSK-MG

$10 \% \lg \mathrm{G} 1, \quad$ Neuromuscular

Yes. Block of MuSK-Lrp4 and

lgG1/2? MuSK

$(2-28)$

domain

junction reduced AChR clustering, block of MuSK-ColQ interaction

serum and $\lg G 4$, active abnormalities at the

ndocytosis? Block of etrograde signaling?

CIDP

Ig-like domain
(protein core,

Paranodal axoglial Yes. Block of contactin/Casp

Yes, passive trans NMJ

(29-35) glycosylation

\section{Pemphigus}

independent)

foliaceus

Dsg1

$\mathrm{N}$-terminal

and NF155 interaction, paranode of lgG4

dismantling

Nerve: transverse band N/A

loss and paranodal loop

detachment

Pemphigus Dsg3
vulgaris

$\begin{array}{ll}\operatorname{lgG1}, 2,3, & \text { Keratinocytes } \\ \lg A & \begin{array}{l}\text { mostly in superfici } \\ \text { layers of the skin } \\ \text { Keratinocytes } \\ \text { mostly in basal/ } \\ \text { parabasal layers of } \\ \text { the skin }\end{array} \\ \operatorname{lgG1}, 2,3, & \text { IgG in blood } \\ \operatorname{lgM}, \lg A & \begin{array}{l}\text { circulation } \\ \text { (ADAMTS13 is a } \\ \text { secreted protease) }\end{array}\end{array}$

Yes. Block of cell adhesion, cell

Yes, several different Antibodies in

Antibodies in
circulation, patie

lgG1, Dsg clustering (36-57)

domains, others

teciation in cultured

models, e.g., passive

skin and mucosal

and endocytosis, and

skin explants. Pathogenicity was patient abs (IgG4). Also keratinocytes

keratinocyte signaling educed after depletion of lgG4 passive transfer from pregnant women to the fetus

\begin{tabular}{lllll}
\hline $\begin{array}{l}\text { Thrombotic } \\
\text { thrombocytopenic }\end{array}$ & ADAMTS13 & 5 small solvent- & $\operatorname{lgG1}, 2,3$, & $\operatorname{lgG}$ in blood \\
purpura & $\begin{array}{l}\text { exposed loops } \\
\text { in the spacer }\end{array}$ & $\operatorname{lgM}, \operatorname{lgA}$ & circulation \\
& domain, others & & (ADAMTS13 is a \\
& & secreted protease)
\end{tabular}

Yes. Cloned lgG4 blocked ADAMTS13 protease activity which leads to von Willebrand domain, others Factor (VWF) accumulation and

Yes, transfection

with recombinant

anti-ADAMTS13 scFv

cloned from patients,

passive transfer of

with relapse,

culating antigen/

microthrombosis

mAbs to baboons

ome patients have

exclusively lgG4

Yes. IgG1 cloned from (58-69) patients also blocked ADAMTS13 activity.

IgG, IgM: other

mechanisms may

include complement activation and clearing

of ADAMTS13 from

the circulation

\begin{tabular}{|c|c|c|c|c|c|c|c|c|c|}
\hline \multicolumn{10}{|c|}{ Class II diseases } \\
\hline $\begin{array}{l}\text { Encephalitis, } \\
\text { Morvan's } \\
\text { syndrome }\end{array}$ & Lgi1 & $\begin{array}{l}\text { Leucine-rich } \\
\text { repeat and EPTP } \\
\text { repeat domains }\end{array}$ & $\lg G 1,2$ & $\begin{array}{l}\text { Synaptic cleft of } \\
\text { CNS neurons, } \\
\text { hippocampal } \\
\text { neurons }\end{array}$ & $\begin{array}{l}\text { Unclear. Serum: block of } \\
\text { Lgi1-ADAM22 interaction and } \\
\text { reduction of AMPA receptors } \\
\text { in vitro, excitation of hippocampal } \\
\text { CA3 pyramidal cells ex vivo }\end{array}$ & N/A & $\begin{array}{l}\text { Brain atrophy in } \\
\text { encephalitis-associated } \\
\text { regions }\end{array}$ & $\begin{array}{l}\text { CD8+ T cells, } \\
\text { complement activation }\end{array}$ & (70-78) \\
\hline CIDP, AIDP & $\begin{array}{l}\text { Neurofascin } \\
155\end{array}$ & $\begin{array}{l}\text { Fibronectin } \\
\text { type III domains } \\
\text { (FN3, FN4), } \\
\text { N-glycosylated }\end{array}$ & $\begin{array}{l}\lg G 1,2,3 \\
\lg M, \text { and } \\
\lg A\end{array}$ & $\begin{array}{l}\text { Central and } \\
\text { peripheral } \\
\text { paranodes }\end{array}$ & $\begin{array}{l}\text { No. Suspected: block of NF155- } \\
\text { CNTN1-CASPR1 interaction }\end{array}$ & N/A & $\begin{array}{l}\text { Sural nerve: paranodal } \\
\text { demyelination }\end{array}$ & $\mathrm{N} / \mathrm{A}$ & $(32,79-85)$ \\
\hline $\begin{array}{l}\text { CNS and PNS } \\
\text { disorders }\end{array}$ & CASPR2 & $\begin{array}{l}\mathrm{N} \text {-Terminal } \\
\text { discoidin } \\
\text { and laminin } \\
\gamma 1 \text { modules } \\
\text { of Caspr2 } \\
\text { (glycosylation } \\
\text { independent) }\end{array}$ & $\begin{array}{l}\lg G 1 \text { in } \\
12-63 \%\end{array}$ & $\begin{array}{l}\text { Juxtaparanodal } \\
\text { region of } \\
\text { myelinated axons, } \\
\text { hippocampal } \\
\text { GABAergic } \\
\text { interneurons }\end{array}$ & $\begin{array}{l}\text { No. Suspected: serum could } \\
\text { affect Gephyrin clustering } \\
\text { by blocking TAG1-Caspr2 } \\
\text { interaction }\end{array}$ & $\mathrm{N} / \mathrm{A}$ & $\begin{array}{l}\text { IgG depositions in brain } \\
\text { biopsy of } 1 \text { patient (but } \\
\text { also complement) }\end{array}$ & $\begin{array}{l}\text { Complement } \\
\text { depositions and } \\
\text { immune cell infiltrates } \\
\text { in brain biopsy in } 1 \\
\text { patient }\end{array}$ & (86-96) \\
\hline
\end{tabular}


TABLE 1 | Continued

\begin{tabular}{|c|c|c|c|c|c|c|c|c|c|}
\hline Disease & Antigen & Epitope & $\begin{array}{l}\text { Other } \\
\text { antibodies }\end{array}$ & $\begin{array}{l}\text { Antibody binding } \\
\text { to affected organ }\end{array}$ & $\begin{array}{l}\text { Pathogenic mechanism of } \\
\text { IgG4 }\end{array}$ & $\begin{array}{l}\text { Active immunization } \\
\text { or passive transfer } \\
\text { model }\end{array}$ & $\begin{array}{l}\text { Biopsy/imaging } \\
\text { finding }\end{array}$ & $\begin{array}{l}\text { Other pathogenic } \\
\text { mechanisms }\end{array}$ & References \\
\hline $\begin{array}{l}\text { Membranous } \\
\text { nephropathy }\end{array}$ & PLA2R & $\begin{array}{l}\text { Conformational } \\
\text { epitope in tertiary } \\
\text { structure of CysR } \\
\text { domain, some } \\
\text { also in CTLD1 } \\
\text { and CTLD7 }\end{array}$ & $\lg \mathrm{lg}_{1,3}$ & Podocytes (kidney) & $\begin{array}{l}\text { No. Suspected: atypical } \\
\text { complement activation via the } \\
\text { lectin pathway by lgG4 (serum/ } \\
\text { biopsies/purified lgG4, data not } \\
\text { published). Block of podocyte } \\
\text { adhesion to collagen IV? }\end{array}$ & $\begin{array}{l}\text { No, due to technical } \\
\text { challenges: PLA2R is } \\
\text { not expressed in rodent } \\
\text { podocytes }\end{array}$ & $\begin{array}{l}\text { PLA2R-lgG in patient } \\
\text { kidney biopsies }\end{array}$ & $\begin{array}{l}\text { lgG1/3, classical } \\
\text { complement activation }\end{array}$ & $(97-109)$ \\
\hline $\begin{array}{l}\text { Membranous } \\
\text { nephropathy }\end{array}$ & THSD7A & $\begin{array}{l}\mathrm{N} / \mathrm{A}, \\
\text { conformational } \\
\text { epitope }\end{array}$ & $\lg G 1,3$ & Podocytes (kidney) & $\begin{array}{l}\text { Unclear, possibly a functional } \\
\text { block of cell adhesion or altered } \\
\text { signal transduction. Changes } \\
\text { in architecture in cultured } \\
\text { podocyte cells induced by lgG. } \\
\text { Detachment and apoptosis of } \\
\text { THSD7A overexpressing HEK293 } \\
\text { cells }\end{array}$ & $\begin{array}{l}\text { Yes, passive transfer } \\
\text { of purified human or } \\
\text { rabbit anti-THSD7A } \\
\text { to mice, absence } \\
\text { of complement } \\
\text { deposition, altered } \\
\text { podocyte architecture, } \\
\text { increased stress fiber } \\
\text { formation, activation } \\
\text { of signaling at focal } \\
\text { adhesions }\end{array}$ & $\begin{array}{l}\text { Renal biopsy: IgG4 } \\
\text { staining }\end{array}$ & $\begin{array}{l}\lg \mathrm{G} 1 / 3 \text { ? Complement } \\
\text { staining (C5b-9) }\end{array}$ & $(110-118)$ \\
\hline \multicolumn{10}{|l|}{ Class III diseases } \\
\hline $\begin{array}{l}\text { Goodpasture } \\
\text { syndrome }\end{array}$ & $\begin{array}{l}\text { Type IV } \\
\text { collagen }\end{array}$ & $\begin{array}{l}\text { Alpha } 3 \text { chain of } \\
\mathrm{NCl} \text { domain }\end{array}$ & $\begin{array}{l}\lg G 1,2, \\
3 \text { (in few } \\
\text { patients) }\end{array}$ & $\begin{array}{l}\text { Glomerular } \\
\text { basement } \\
\text { membrane (kidney), } \\
\text { lungs not tested }\end{array}$ & N/A & $\mathrm{N} / \mathrm{A}$ & $\begin{array}{l}\text { IgG deposition in } \\
\text { glomerular basement } \\
\text { membrane (kidney } \\
\text { biopsy) }\end{array}$ & $\mathrm{N} / \mathrm{A}$ & $(119-123)$ \\
\hline CIDP & CASPR1 & N/A & $\lg G 1$ & $\begin{array}{l}\text { Paranodes (murine } \\
\text { teased fibers) }\end{array}$ & N/A & $\mathrm{N} / \mathrm{A}$ & Axonal degeneration & & $(35,124)$ \\
\hline DPPX encephalitis & DPPX & $\begin{array}{l}\text { Extra- and intra- } \\
\text { cellular domains } \\
\text { (DPPX-L/S/X) }\end{array}$ & $\lg \mathrm{lg}_{1,2}$ & $\begin{array}{l}\text { Somatodendritic } \\
\text { and perisynaptic } \\
\text { neuronal surface, } \\
\text { hippocampus, } \\
\text { small intestine }\end{array}$ & $\begin{array}{l}\text { No. Modulation/loss of DPPX } \\
\text { and Kv4.2 by total lgG likely by } \\
\text { lgG1/2. Hyperexcitation of enteric } \\
\text { neurons. }\end{array}$ & & $\begin{array}{l}\text { Cerebrospinal (CSF) } \\
\text { pleocytosis, increased } \\
\text { IgG index or oligoclonal } \\
\text { bands, and abnormal } \\
\text { brain MRI }\end{array}$ & $\begin{array}{l}\text { Modulation/loss } \\
\text { of DPPX and } \\
\text { Kv4.2 by total IgG } \\
\text { likely by lgG } 1 / 2 \text {. } \\
\text { Hyperexcitation of } \\
\text { enteric neurons }\end{array}$ & $(125-129)$ \\
\hline Iglon5 parasomnia & Iglon5 & $\begin{array}{l}\text { Ig-like domain } 2 \\
\text { (non-glycosylated) }\end{array}$ & $\lg G 1,2$ & Rat brain neuropil & $\mathrm{N} / \mathrm{A}$ & $\mathrm{N} / \mathrm{A}$ & $\begin{array}{l}\text { Brainstem, } \\
\text { hypothalamus: neuronal } \\
\text { loss, deposits of } \\
\text { hyperphosphorylated } \\
\text { tau }\end{array}$ & $\begin{array}{l}\operatorname{lgG} 1 \text { induces } \\
\text { endocytosis of Iglon5 }\end{array}$ & $(130-135)$ \\
\hline
\end{tabular}

ADAMTS13, disintegrin and metalloproteinase with thrombospondin motifs 13; Caspr, contactin-associated protein; CIDP, chronic inflammatory demyelinating polyradiculoneuropathy; CNTN1, contactin 1; DPPX, dipeptidyl peptidaselike protein 6; Dsg1, desmoglein 1; Dsg3, desmoglein 3; Ig, immunoglobulin; Iglon5, IgLON family member 5; Lgi1, leucine-rich, glioma-inactivated 1; Lrp4, low-density lipoprotein receptor-related protein 4; MUSK, muscle-specific kinase; PLA2R, phospholipase A2 receptor; sCFV, single chain variable region fragments; THSD7A, thrombospondin type-1 domain-containing 7A; VWF, von Willebrand factor. 
A

A
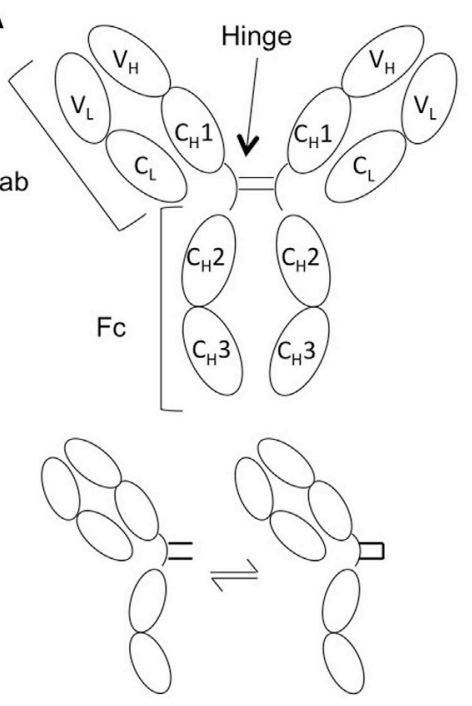

Interchain

S-S bonds

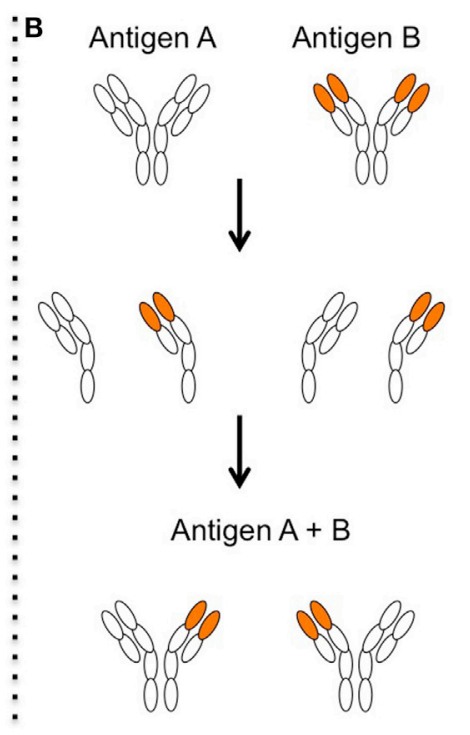

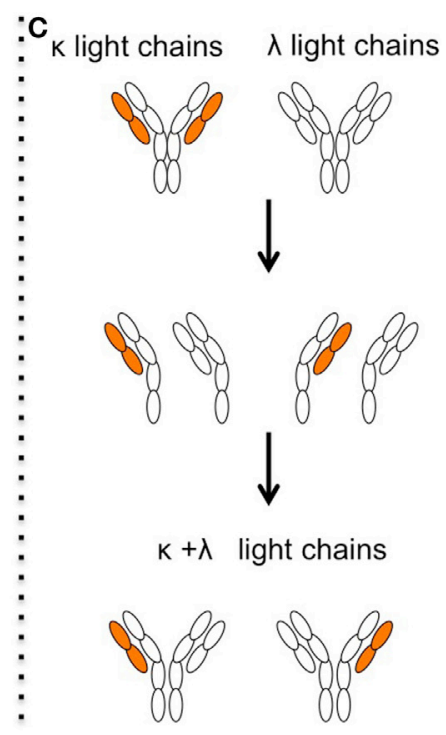

FIGURE 1 | The structure of IgG4 allows for Fab-arm exchange (FAE). (A) Structure of IgG4. One single amino acid change in the IgG4 hinge allows for greater structural flexibility and two different hinge isomers, with either interchain disulfide bonds that connect the two different heavy chains, or intrachain disulfide bridges within the same heavy chains. Under reducing conditions, the two isoforms are in a dynamic equilibrium. Figure adapted from Ref. (147). (B) When the two half-antibodies (HL) are not connected by interchain disulfide bonds they can then split up. $\mathrm{HL}$ of different idiotypes recombine randomly, resulting in antibodies that recognize two different antigens and are bispecific. (C) Antibodies are produced with light chains of either $\kappa$ or $\lambda$ type. Upon FAE, antibodies with both $\kappa$ and $\lambda$ light chains can be generated.

antigens instead of two antigens of the same kind [Figure 1B (166, 167)]. As a consequence, IgG4 is not able to activate the classic complement pathway or activate immune cells as discussed in the part of the protective role of IgG4 in immunity. The following reviews are suggested for further reading on IgG4 structure (147, 168-170).

\section{FAE: Regulation and Kinetics}

Fab-arm exchange seems to occur spontaneously in the body, since antibodies that are bispecific for two different allergens can be found in allergy patients (166). Here, endogenous IgG4 was able to cross-link two different allergens suggesting that an exchange between two distinct allergen-specific IgG4 molecules (birch and cat allergen) had taken place. FAE also occurred between human IgG and therapeutic, humanized antibodies (natalizumab) given as therapy to patients; here, the therapeutic antibodies exchanged half-molecules in vivo with endogenous IgG4 (171, 172). Bi-specific IgG4 was also detected in healthy probands, as IgG4 possessing both a $\lambda$ and a $\kappa$ light chain simultaneously was found in their serum [Figure 1C (173)]. FAE is inducible in vitro using reducing agents, such as glutathione (GSH) at concentrations of $1 \mathrm{mM}$ and less $(166,171,174-176)$. It is not known if and how FAE is regulated, or where it occurs in the body. The concentrations of GSH in human serum are too low to allow for efficient FAE, but other yet unidentified compartments in the body might provide the required GSH concentrations, e.g., human red blood cells, as they contain approximately $1 \mathrm{mM}$ GSH (177).
In vitro-induced FAE occurs rapidly, in less than an hour (167), but in vivo it could take hours to days. The therapeutic monoclonal anti-integrin antibody natalizumab was found to exchange Fab arms in patients with endogenous IgG4 (172), with quantitative data obtained by injection of natalizumab into rats demonstrated an exchange half-life of less than 6 h (178). Human IgG4 has a metabolic half-life of around 21 days (179). Calculations led by Peter Molenaar based on these findings using first-order kinetics suggest that up to $99 \%$ of IgG4 should be bispecific in the body (17). There is further evidence: in IgG4 the $\kappa$ light chain is more commonly used with a 3:1 $\kappa: \lambda$ ratio. After FAE, IgG4 can harbor a $\kappa$ and a $\lambda$ light chain simultaneously (Figure 1C). The chance of a $\kappa$-half molecule to exchange with another $\kappa$-half-molecule is, therefore, more likely than the exchange with a $\lambda$-half-molecule, leading to a "silent" bispecificity hidden in the $\kappa / \kappa$ and $\lambda / \lambda$ fractions (173). The exchange is thought to be random. Calculating recombination probabilities using a Punnet square and assuming a $100 \%$ exchange rate, we expect a ratio of $9: 6: 1(\kappa / \kappa: \kappa / \lambda: \lambda / \lambda)$. That means $37.5 \%$ of IgG4 would be $\kappa / \lambda$ bispecific, which is close to the values measured in one study with healthy individuals (173). Taken together, it suggests that the majority of IgG4 in the human body is bispecific under normal circumstances. Despite the reduced avidity of IgG4, autoantibody binding can be demonstrated in tissue- and cell-based assays in vitro, e.g (3, 72, 88, 99)., perhaps due to the high affinity of the antibody with a Kd that can be in the picomolar range (180). Bispecificity also has functional consequences, as bispecific IgG4 is unable to divalently bind and cross-link one single species of antigen. 


\section{IgG4 Fc-Fc Interactions}

The Fc region of IgG4 is also able to directly interact with IgG by Fc-Fc interactions, but only if the binding partner is immobilized on a solid phase (181-183). The relevance of this interaction is not understood, but notably occurs in rheumatoid arthritis, IgG4related disease (IgG4-RLD), and membranous nephropathy $(\mathrm{MN})$, the latter being proposed as an IgG4 autoimmune disease (184-186). It is possible that IgG4 containing immune complexes could form by this mechanism; these would not otherwise form by divalent binding and cross-linking due to the bispecificity of the antibody (163). Modifications of the Fc region of IgG4 induced the formation of artificial hexameric complexes via noncovalent interactions that were able to bind $\mathrm{Clq}$ and activate the classical complement pathway (187). Whether this is relevant for pathophysiology of IgG4 is unclear.

\section{IgG4 Has a Protective Role in Immunity}

IgG4 and IgE are usually produced in response to chronic exposure to antigens (188). The production of IgE and IgG4 is stimulated by $\mathrm{T}_{\mathrm{h}} 2$ cytokines IL- 4 and IL-13. Furthermore, the additional presence of IL-10 is thought to tip the balance toward IgG4 production and IgE inhibition (189-192). In addition, secretion of IL-10 by regulatory $\mathrm{T}$ cells was also found to induce IgG4 rather than IgG1 production (193) and a majority of isolated IL-10-producing regulatory B cells produced IgG4 in contrast to other B-cell subsets (194). These findings link IgG4 with anti-inflammatory tolerance mechanisms [discussed in more detail here (147)]. At present, most literature reveals that IgG4 has an anti-inflammatory function. It has been shown that its levels only rise slowly after chronic exposure to antigen (195-197) or after allergy immunotherapy (198). Thereafter, IgG4 seems to protect against antibodies of other IgG subclasses by competition for antigen without exerting an effector function, thus blocking the epitope to prevent the harmful effect of other antibody classes or subclasses [Figure 2 (196-204)]. It has also been shown that passive transfer of IgG4 derived from hyperimmune beekeepers is clinically protective in allergy patients (205, 206) and protects mice from the effects of lethal africanized honey bee venom (207). Similarly, IgG4 subclass autoantibodies against the AChR protect against the pathogenic effects of IgG1 of the same idiotype in rhesus monkeys (166). The immunological inertness and the anti-inflammatory effect of IgG4 make it an unlikely subclass in the context of autoimmunity (Figure 2). In many cases [although there are exceptions (49)], antigen crosslinking and endocytosis in the context of autoimmunity rely on divalent binding [Figure 2 (208-213)], which IgG4 cannot do (2, $3,166)$. IgG4 does not form immune complexes that would stimulate antigen-presenting cells and mount an immune response nor does it activate the classical complement system $(166,170$, 214). Furthermore, IgG4 inhibits immune precipitation by IgG1 antibodies $(163,200)$. Only pathogenic mechanisms that are independent of Fc effector functions can be exerted by IgG4, e.g., a block of protein-protein interaction or a direct activation or

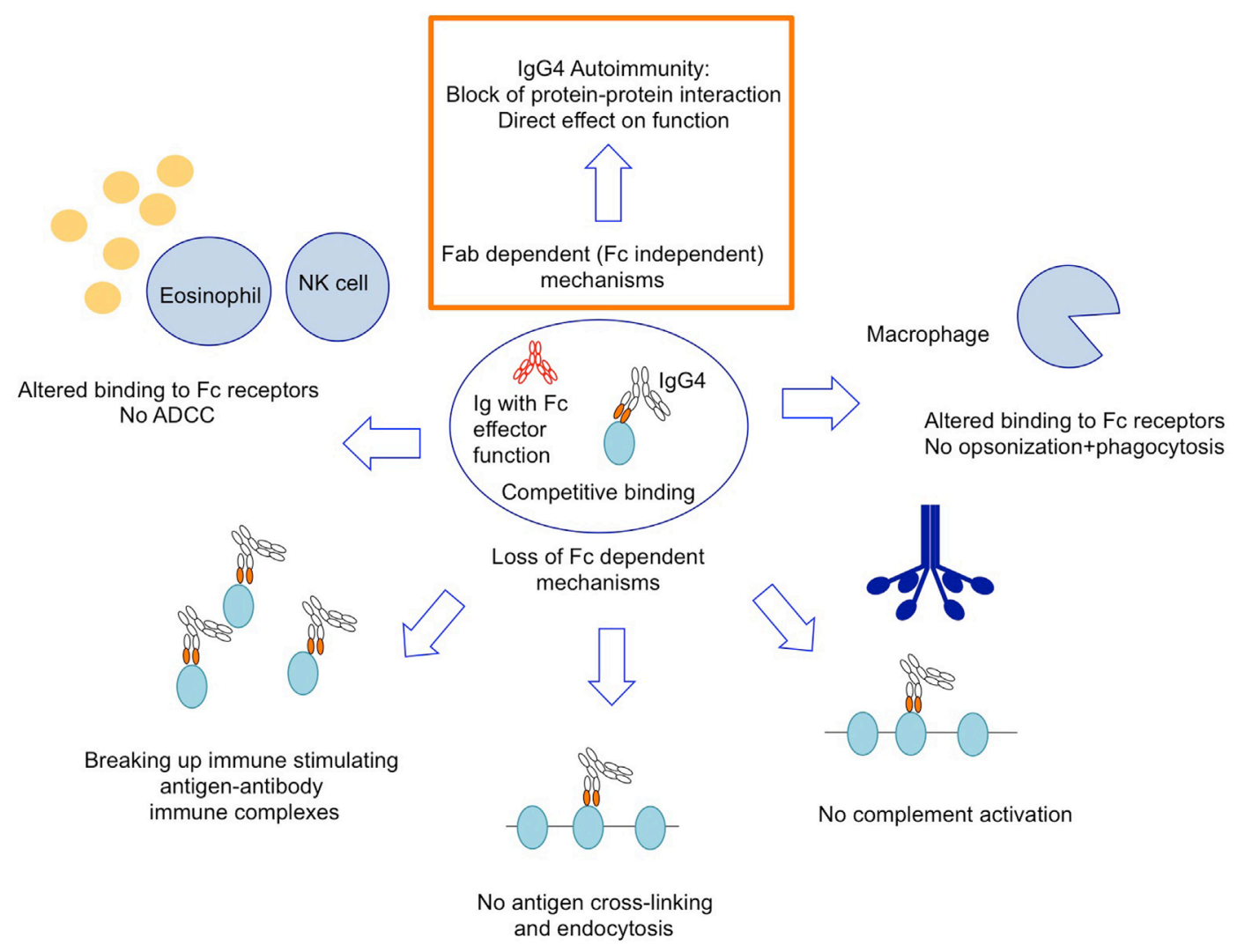

FIGURE 2 | IgG4 autoantibodies rely on pathogenic mechanisms that are independent of Fc effector function or multivalent binding. 


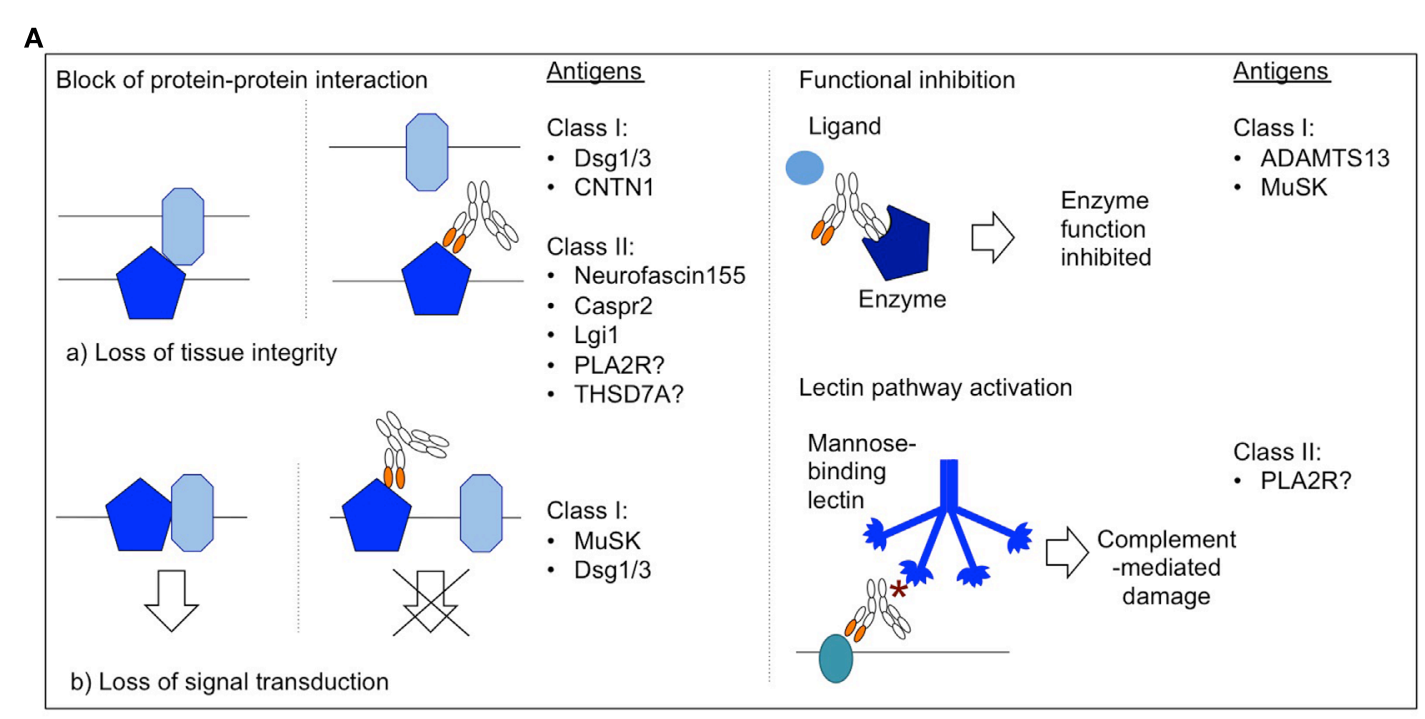

B

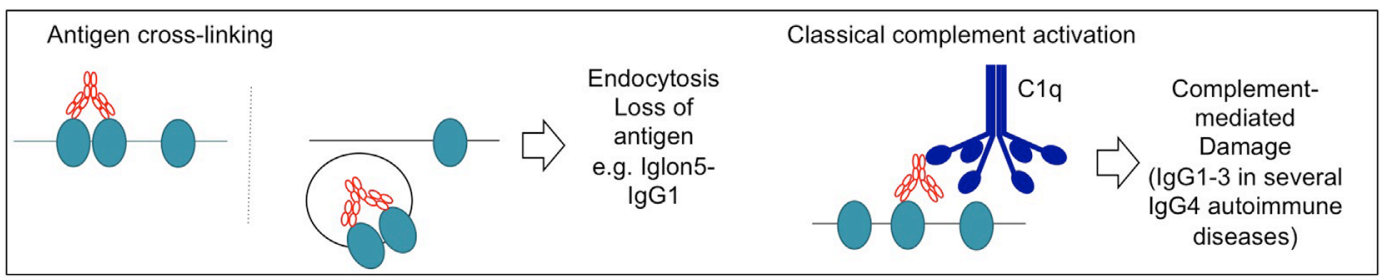

FIGURE 3 | Selected pathogenic mechanisms of IgG autoantibodies. (A) Pathogenic mechanisms of IgG4 autoantibodies. * $=$ hypogalactosylated glycan side chain of IgG4. (B) Selected pathogenic mechanisms of IgG1-3 autoantibodies.

inactivation of enzymes or receptors by competitive or allosteric binding (Figure 3A).

\section{DEFINITION AND VALIDATION OF IgG4 AUTOIMMUNE DISEASES}

Autoantibodies are in general considered pathogenic when they bind an extracellular antigen in the target organ, e.g., the extracellular portion of a transmembrane antigen, and have a direct pathogenic effect, either directly on the target antigen (e.g., by induction of endocytosis or blocking of antigen function) or on the whole organ by recruitment and activation of complement or immune cells that attack the tissue $(1,215)$. Antibodies against intracellular antigens are not considered to be pathogenic as they are generally inaccessible (215), although they can be valuable biomarkers (216). IgG4 subclass autoantibodies are certainly unexpected culprits in autoimmunity. Particularly, as IgG4 can arise during an immune-dampening response to pathogenic antibodies of other classes and subclasses, candidate diseases should be carefully investigated to determine the pathogenic status of autoreactive IgG4. Using a modification of the postulates by Witebsky, Rose and Bona, and taking into account remarks by Naparstek and Plotz $(215,217,218)$, the individual IgG4 autoantibodies in IgG4 autoimmunity were tested to validate the status of IgG4 autoimmunity.
Several aspects should be considered to define IgG4 autoimmunity:

(A) Indicators for antibody-mediated autoimmunity

1. Autoantibodies with specificity for an extracellular antigen are present in the affected organ.

2. A pathogenic mechanism for antibodies is demonstrated in vitro.

3. The autoimmune disease can be reproduced in experimental animals by passive transfer of patient serum or purified abs or active immunization with antigen.

4. Clinical cues for autoimmunity are present such as HLA association, genetic clustering of other autoimmune diseases in the family, and the clinical improvement of the patients after therapies that reduce autoantibody levels, such as plasma exchange or B-cell depletion therapy.

(B) Specific indicators for IgG4 pathogenicity

1. Autoantibodies of IgG4 subclass against extracellular antigen are present.

2. A pathogenic mechanism for IgG4 can be demonstrated in vitro. IgG4 could be purified from patient serum, and the purity of isolated IgG4 should be validated; ideally also the IgG4-depleted IgG1-3 fraction should be used as a control group to ensure the effects derived from IgG4. Alternatively, cloned patient antibodies 
from IgG4+ B-cells could be used, although these may not be representative of the whole autoimmune B-cell population.

3. Reproduction of disease in animals by passive transfer of purified IgG4 from patients, monoclonal IgG or single chain variable region fragments $(\mathrm{scFv})$ cloned from IgG4+ B-cells of patients.

The 14 proposed IgG4 autoantibodies and their associated diseases were evaluated according to these aspects (Table 1). With particular focus on the pathogenicity of IgG4 autoantibodies, three classes emerged with different levels of evidence and also with different likeliness of IgG4 pathogenicity. Class I diseases fulfill two or three postulates of IgG4 pathogenicity (B.1-3), here the pathogenicity of IgG4 autoantibodies could be proven by passive transfer of patient IgG4, or an IgG4 pathogenic mechanism was demonstrated in vitro (in most cases this is was a blocking effect). Class II diseases fulfill one postulate for IgG4 pathogenicity (B.1), but there exists substantial circumstantial evidence that would be in line with pathogenicity of IgG4. Examples would be if IgG4 levels correlated with disease severity or the presence of a known pathogenic mechanism that relies on functional blocking. Class III diseases still fulfill one postulate of IgG4 pathogenicity (B.1) but have the least supportive evidence for IgG4 pathogenicity, either because the pathogenic mechanism relies on divalent binding or is unknown. At this point, a conclusion regarding IgG4 pathogenicity cannot be drawn for class II and III diseases, and more studies are required to validate pathogenicity of their IgG4 autoantibodies.

\section{Class I Diseases}

One of the best-studied IgG4-mediated diseases is pemphigus. Here, autoantibodies bind to transmembrane proteins of keratinocytes, which leads to loss of cell-cell adhesion and blistering of the skin (acantholysis). The antigenic targets define different subforms of disease. In pemphigus foliaceus, the antigenic target is desmoglein 1 (Dsg1), which is expressed at high concentrations in the superficial layers of the epidermis; in pemphigus vulgaris, the mucosal-dominant type antibodies target desmoglein 3 (Dsg3) in basal and parabasal layers of the skin. Patients with pemphigus vulgaris of the mucocutaneous type have antibodies against both Dsg1 and Dsg3 $(38,39)$. Anti-Dsg autoantibodies are predominantly IgG4 $(36,37)$. They bind to extracellular epitopes and disrupt cell-cell adhesion, as seen in vitro where they induced cell sheet dissociation of cultured human keratinocytes $(57,219)$ and human skin explants (51). Additionally, the disease could be reproduced by passive transfer of monoclonal patient-derived antibodies that were of IgG4 subclass $(42,43)$. This means that pathogenicity of IgG4 could be demonstrated in the absence of patient antibodies of other IgG subclasses. Also, depletion of IgG4 reduced pathogenicity of patient serum in one study (220). Nevertheless, this does not mean that IgG4 is the exclusive pathogenic entity, and one study demonstrated that cloned patient IgG1 against Dsg3 was as pathogenic as IgG4 (221). The role of other IgG subclasses in IgG4 autoimmunity is discussed below in more detail. There are in fact several different disease models to investigate pathophysiology of pemphigus by passive or adoptive transfer [reviewed by Ref. (52)]. Maternal antibodies can also transfer to the fetus and cause neonatal pemphigus (54). Antibodies to Dsg1/3 may also affect signal transduction pathways that affect cytoskeleton rearrangement and modulate cell adhesion in keratinocytes, and several targets have been proposed $(51,222-228)$. Indeed, the MAPK signaling was suggested as potential therapeutic target in pemphigus (225), which can in part modulate the disruption of cell adhesion caused by pathogenic pemphigus autoantibodies (229).

Muscle-specific kinase MG is an autoimmune disease of the neuromuscular synapse hallmarked by fatigable muscle weakness. The autoantibodies target MuSK, a protein at the neuromuscular junction. Approximately $90 \%$ of the antibodies are of IgG4 subclass $(3,16)$, and the pathogenic mechanism of MuSK IgG4 is known and can be demonstrated in vitro with purified IgG4 $(2,3)$. Notably, the pathogenic effect was exclusive for IgG4 subclass antibodies. Passive transfer of purified IgG4 reproduced the disease in experimental animals (4), as did active immunization of complement-deficient mice (5). There is also evidence for a genetic predisposition in these patients $(14,15)$. Binding of antibodies to MuSK similarly affects its function as tyrosine kinase and organizer of neuromuscular junction development and maintenance. As the binding of the agrin coreceptor low-density lipoprotein receptor-related protein 4 (Lrp4) to MuSK is blocked by MuSK-IgG4 $(2,3)$, MuSK autophosphorylation in response to agrin is inhibited (2), which impairs its ability not only to induce clustering of the $\operatorname{AChR}(3,27)$ but also to maintain the preexisting clusters (3). This leads to reduced densities of the AChR at the synapse and reduced efficiency of neuromuscular transmission, thus causing fatigable muscle weakness. A recent study demonstrated that inhibiting MuSK dephosphorylation counteracted the effects of MuSK antibodies in vitro, which would be an interesting new therapeutic strategy (230). Interestingly, the MuSK antibodies also modify the cross talk between motoneuron and muscle, as presynaptic abnormalities were observed in patients and passive transfer animal models, and led to a reduced quantal release of acetylcholine neurotransmitter into the synaptic cleft $(5,21,22$, $26,231)$. The affected retrograde signaling pathway is not known, but as Lrp4 may be part of a retrograde signaling pathway (232, 233), it is very likely that the Lrp4-MuSK interaction plays a role, perhaps by anchoring Lrp4 at the synapse.

Disintegrin and metalloproteinase with thrombospondin motifs 13 (ADAMTS13) is a protease in the blood circulation that cleaves von Willebrand factor (vWF). In TTP, antibodies against the spacer domain of ADAMTS13 inhibit proteolysis of vWF (60, 234), which leads to accumulation of vWF, binding to platelets and causing microthrombosis. Since the inhibitory antibodies recognize the spacer domain that is also required for binding to vWF, the functional block could be due to blocked protein-protein interaction. IgG4 (but also IgG1) antibodies cloned from TTP patients by EBV immortalization demonstrated pathogenicity in vitro in assays measuring ADAMTS13 activity (69). Also, several patient-derived $\mathrm{scFv}$ were shown to be pathogenic when expressed in mice, albeit the original subclass of the patient antibodies is unknown (59). There is also additional circumstantial evidence that pathogenic antibodies of IgG4 subclass exist in TTP 
as IgG4 levels are associated with relapse and some patients have exclusively IgG4 autoantibodies (235).

Contactin 1 (CNTN1), together with contactin-associated protein 1 (Caspr1), is expressed on the axonal surface and together they bind to neurofascin 155 on the surface of oligodendroglia (236-239). They are cell adhesion molecules at the axoglial junction of myelin sheaths that are important for efficient nerve impulse propagation along myelinated axons. Antibodies against CNTN1 of IgG4 and IgG1 subclass are present in chronic inflammatory demyelinating polyradiculoneuropathy (CIDP) (29, $34,35,124)$ and were proven to be pathogenic. Autoantibodies recognize CNTN1 in the paranodal axoglial junctions of motoneurons and block interaction of neurofascin 155 with CNTN1 in the CNTN1/Caspr1 complex (30). This leads to transverse band loss and paranodal loop detachment in the peripheral nerves. Pathogenicity of IgG4 was proven by passive transfer of purified IgG4 to Lewis rats (31) with loss of paranodal clusters that contain CNTN1, Caspr1, and neurofascin 155 and impaired motor nerve conduction.

\section{Class II Diseases}

Membranous nephropathy, a cause of proteinuria and nephrotic syndrome, is hallmarked by immune deposits containing IgG [predominantly IgG4 antibodies to the phospholipase A2 receptor (PLA2R) in primary MN], autoantigens such as PLA2R, and complement beneath the basal surface of podocytes in the kidney. PLA2R-IgG4 was proposed to have a unique mechanism of complement activation via the lectin pathway $(98,99,103,108,109)$. This activation is hypothesized to derive from galactose-deficient side chains in PLA2R-IgG4 $(97,98)$ that might recruit mannosebinding lectin (MBL), which is also seen in rheumatoid arthritis (240) and IgA nephropathy (241). MBL binding leads to the activation of the lectin pathway and formation of the membraneattack complex (103). Preliminary data by Beck and Salant from experiments with purified IgG4 from patients with primary $\mathrm{MN}$ showed that more of the IgG4 glycan chains lacked terminal galactose residues than did the IgG4 from control subjects and demonstrated increased binding of MBL to PLA2R-IgG4 (108). Additional evidence comes from a more recent study, where MBL deposition in glomeruli correlated with IgG4 positivity in biopsies from Japanese MN patients (109). A recent study by the group of Andreas Kistler demonstrated hypogalactosylated glycan side chains for IgG4, IgG induced complement-mediated injury to PLA2R-expressing podocytes in vitro and its prevention by MASP inhibitors, which adds further evidence to this unusual mechanism (poster presentation at the 2017 American Society of Nephrology meeting). However, both the Kistler and the Ma studies have not yet been published in peer-reviewed journals and need further investigation. IgG4-mediated activation of the lectin pathway may not be the only pathogenic mechanism, as one patient with characteristic PLA2R-IgG4-positive MN was deficient for MBL but revealed complement activation via the alternative pathway (242), and a small fraction of patients is negative for PLA2R-IgG4 (243). Additionally, a monoclonal IgG3 kappa with specificity for PLA2R was able to cause $\mathrm{MN}$ in the native kidney and the allograft via the classical pathway (244). An additional blocking mechanism was proposed since antibodies against PLA2R in MN were found to block adhesion of podocytes to collagen IV (245). In another study, PLA2R, however, was not found to bind collagen IV or I in general $(106,246)$. Furthermore, attempts to reproduce the disease in rodents by passive transfer have been unsuccessful, since the podocytes of rodent glomeruli do not express PLA2R [summarized by Ref. (247)]. Therefore, further studies are required to validate this finding and pinpoint the mechanism to IgG4.

Thrombospondin type-1 domain-containing 7A is expressed in glomeruli in the kidney and is another antibody targeted in $\mathrm{MN}(110,113,114,118)$. Histologically, a thickening of the glomerular basement membrane with IgG and complement deposition can be observed. Anti-THSD7A antibodies were predominantly IgG4 (but also IgG1) $(110,116)$ and in vitro were shown to affect cytoskeletal architecture with the formation of stress fibers in cultured primary murine podocyte cells and could also induce detachment of THSD7A overexpressing HEK293 cells (111). Passive transfer of patient serum to mice led to proteinuria with late complement activation, but transient proteinuria in the absence of complement involvement was induced after passive transfer of THSD7A affinity-purified patient antibodies (111). Passive transfer of anti-THSD7A antibodies generated in rabbits could reproduce disease independent of complement activation (112). Taken together, there is evidence that THSD7A antibodies affect podocyte attachment, perhaps by a (reversible) blocking effect, but also that complement activation via C1q or lectinbinding pathway as a second pathogenic mechanism plays a role.

In three different neurological disorders with IgG4 subclass antibodies, targeting leucine-rich, glioma-inactivated 1 (Lgi1), contactin-associated protein 2 (Caspr2), and Neurofascin155, respectively, a pathogenic mechanism has been suggested that is based on the block of protein-protein interaction $(70,80,87$, $93,248)$. The predominant mechanism of IgG4 antibodies in class 1 IgG4 autoimmune diseases was found to be a blocking mechanism, which may also be associated with a subclass switch to IgG4. It should be kept in mind that a blocking mechanism is not per se restricted to the IgG4 subclass [e.g., Ref. (69)], although it is more commonly associated with IgG4 autoimmunity. In detail, Lgil is expressed at the synaptic cleft of CNS neurons and in hippocampal neurons in culture, like CASPR2, it is part of the voltage-gated potassium channel complex, and antibodies against Lgil are associated with limbic encephalitis (72, 77, 93, 249). Here, serum from patients with Lgil encephalitis led to a block of Lgi1-ADAM22 interaction in vitro, which caused reduced AMPA receptors and excitation of hippocampal CA3 pyramidal cells ex vivo (70). These effects were not yet proven to be IgG4 specific. Caspr2 is expressed in the peripheral and central nervous system, particularly in the juxtaparanodal region of myelinated axons and in hippocampal GABAergic interneurons, and autoantibodies are associated with different clinical syndromes (88, 91, 250-252). It is suspected that the antibodies block the interaction between Caspr2 and TAG-1 and affect inhibitory interneuron function, thus leading to hyperexcitability (87). Importantly, many patients harbor not only IgG4 subclass antibodies against Caspr2 or Lgi1 but also IgG1 and IgG2 (88). Antibodies to neurofascin 155 are thought to have a similar effect to antibodies against CNTN1, with a block of CNTN1/Caspr1-neurofascin 155 interaction affecting 
paranodal structure and causing peripheral neuropathies $(30,79$, $81,84)$.

\section{Class III Diseases}

IgLON family member 5 (Iglon5) is a CNS antigen and is targeted by autoantibodies in Iglon 5 parasomnia, which is a severe autoimmune disease characterized by abnormal sleep behavior. Here, a population of pathogenic IgGlautoantibodies induced endocytosis of Iglon5 (134) (discussed in more detail below). It was demonstrated that purified Iglon5-IgG4 as well as digested Fab fragments did not induce this mechanism. It cannot be excluded that Iglon5-IgG4 antibodies have an additional pathogenic mechanism, but at this moment there is no indication that they are pathogenic at all.

Similarly, in the case of dipeptidyl peptidase-like protein 6 (DPPX) antibodies, the described pathogenic mechanism is the loss of DPPX and associated Kv4.2 from the cell surface, perhaps by antigenic modulation, which would require divalent binding and cross-linking of antigen. Unless an additional pathogenic mechanism is found for DPPX-IgG4, or alternatively, it is demonstrated that the loss of DPPX and Kv4.2 results from a mechanism that does not rely on divalent binding, it is not likely that DPPX encephalitis is an IgG4 autoimmune disease.

Only one patient has been described with IgG4 subclass antibodies against Caspr1 [a second one if antibodies against complexed CNTN1/Caspr1 are considered $(35,124)]$, and at this point not enough data are available to estimate pathogenicity of IgG4. There are also insufficient data available regarding pathogenicity of IgG4 subclass anti-collagen type IV (alpha3NC1 domain) antibodies in Goodpasture syndrome, the most convincing circumstantial evidence being temporal occurrence and reoccurrence of IgG4 autoantibodies and lung hemorrhage (119).

In summary, the pathogenicity of IgG4 in most IgG4 autoimmune diseases has not been proven yet. A key experiment could be the isolation of IgG4 subclass antibodies from patient serum or plasmapheresis material, followed by passive transfer to a suitable animal model, or to use purified IgG4 in already established in vitro models of pathogenicity.

\section{PROPERTIES OF IgG4 AND IgG4 AUTOIMMUNE DISEASES}

One key pathogenic mechanism in antibody-mediated autoimmunity, especially in the peripheral and central nervous system, is the divalent binding, cross-linking, and endocytosis of antigen, as seen with antibodies against AChR, GlyR, NMDAR, and Iglon5 [Figure 3B (134, 208-210, 253)]. The effect is usually lost when using Fab fragments instead of whole IgG1, which underlines the relevance for multivalent binding. A possibility how IgG4 autoantibodies could remain pathogenic by cross-linking and endocytosis would be the loss of FAE, as then monospecific IgG4 could still cross-link and internalize antigen. An example could be the presence of point mutations or sequence variants in the IgG4 hinge or the $\mathrm{C}_{\mathrm{H}} 3$ region that would remove its ability to undergo FAE. This possibility was investigated in several IgG4associated diseases. In IgG4-RLD, sequencing showed that the FAE abolishing variant K409 was not present (254), and a recent study demonstrated high levels of bispecific IgG4 in IgG4-RLD (255). Similarly, IgG4 autoantibodies in rheumatoid arthritis were found to be bispecific (256), and recently we were able to demonstrate the same for an example of IgG4 autoimmunity, as a large proportion of patient-derived MuSK autoantibodies were bispecific as well (17). These are only a few publications yet, and more studies are needed to validate the findings in additional IgG4-associated diseases. Until then, there is no indication that impaired FAE affects IgG4 in IgG4-associated disorders, which suggests that pathogenic mechanisms of IgG4 autoantibodies do not rely on divalent binding. Notably, the authors of the IgG4RLD study suggest increased levels of FAE as a new biomarker. As IgG4-RLD is also associated with elevated levels of IgG4, and up to $99 \%$ of IgG4 are probably bispecific, it would be interesting to test a correlation between IgG4 concentrations and $\kappa / \lambda$ bispecific IgG4. Enrichment of $\kappa / \lambda$ IgG within the total IgG4 population (compared to $\kappa / \kappa$ and $\lambda / \lambda$ antibodies) could indicate a change in light chain usage.

\section{Blocking as a Main Pathogenic Mechanism of IgG4}

Blocking mechanisms are independent of the $\mathrm{Fc}$ domain and as such are the main effector mechanisms for IgG4 autoantibodies (Figure 3A). The binding of antibody to antigen can cause the inappropriate activation or blocking of enzymes or receptors. As examples, blocking antibodies of IgG1-3 subclass prevent binding of the neurotransmitter acetylcholine to the acetylcholine receptor in AChR MG (257-259), blocking antibodies against thyroxin peroxidase reduce production of thyroid-stimulating hormone (TSH) thus causing hypothyroidism (260), while stimulating antibodies against the TSH receptor are associated with hyperthyroidism (261). Functional blocking as a pathogenic mechanism is found in not only the IgG4 autoimmune diseases TTP and MuSK MG but also pemphigus (2, 52, 60, 234).

Block of protein-protein interaction is overall considered a main pathogenic mechanism for IgG4 and was demonstrated in several class I and II IgG4 autoimmune diseases (Figure 3A). The consequence of such a block could be the block of a signal transduction pathway (MuSK, Dsg1/3) or the loss of tissue integrity (e.g., Dsg1/3, Caspr1, and CNTN1). Most IgG4 autoantibodies were found to block protein-protein interaction.

\section{Complement Activation}

Another key mechanism of IgG1-3 autoantibodies is the recruitment of $\mathrm{Clq}$ protein and activation of the classical complement pathway, which leads to complement mediated damage, e.g., by antibodies against AChR or aquaporin 4 [Figure 3B (262-265)]. IgG4 does not bind C1q, but intriguingly, complement activation by the lectin pathway may emerge as a novel mechanism of IgG4 autoantibodies, as it is found in PLA2R-IgG4 with hypogalactosylated glycan side chains [Figure 3A (98, 99, 103, 108, 109)].

\section{IgG4 Autoimmune Diseases}

IgG4 pathogenic mechanisms translate to a range of different disorders that are clinically very diverse. An excellent introduction to the different IgG4 autoimmune diseases can be found here (266). A selection of disease specific reviews is found here 
$(9,52,80,106,235,267-271)$. A good response to B-cell depletion therapy and plasmapheresis has been reported in several IgG4 autoimmune diseases (6-13, 32, 78, 272-274).

\section{Contribution of Other Antibody Classes and Subclasses}

As IgG4 levels usually increase after repeated or strong exposure to antigen, a high level of IgG4 may coexist with (smaller quantities of) pathogenic antibody of other class or subclass (e.g., IgE or IgG1) and could have clinical implications for treatment decisions. Specifically, after the evaluation and classification of the proposed IgG4 autoimmune diseases, it emerged that in most cases several different antibody classes and/or subclasses are present in patient serum (Table 1), with varying degree of potential pathogenicity. Of note, IgG4 concentrations could potentially be overestimated depending on the choice of secondary antibody (16), and crossreactivity between secondary antibodies against IgG4 and IgG2 is also known to occur. A correlation between overall antibody titer and antigen-specific IgG4 titer would increase confidence in the quantification data (3).

Furthermore, pathogenic mechanisms were described for serum or IgG from patients with IgG4 autoimmunity that are likely not caused by IgG4 subclass antibodies as they depend on divalent binding or Fc effector function (Figure 3B, endocytosis of antigen and complement activation) or have been demonstrated using purified or cloned patient IgG1-3 [e.g., Dsg3-IgG1 (221), ADAMTS13-IgG1 (69), Lgi1-IgG3 (275), MuSK-IgG1-3 (3), or Iglon5-IgG1 (134)]. Indications for complement activation were found in several disorders (Table 1).

Particularly interesting are Iglon5 autoantibodies in which an irreversible internalization of Iglon5 was shown. Here, a clear pathogenic mechanism of IgG1, depending on divalent binding (134), was shown. Iglon family members are glucosylphosphatidylinositol-anchored proteins that have a role in membrane stabilization. Iglon5 parasomnia also has an unusual association with tauopathy $(130,276,277)$ linking autoimmunity to neurodegenerative diseases. Combined, these findings led to the current hypothesis that Iglon5-IgG1 antibodies, by antigenic modulation of Iglon5, cause a destabilization of the cytoskeleton. This may affect microtubule stability and hyperphosphorylation of associated tau protein that could lead to the observed tauopathy (276). Whether IgG4 subclass antibodies to Iglon5 are pathogenic at all is unclear, thus making it a class III IgG4 autoimmune disease.

Similarly, DPPX antibodies cause a reversible loss of cell surface-expressed DPPX and Kv4.2, thus leading to hyperexcitation of neurons (127). This requires divalent binding and cross-linking of antigens. As IgG4 is mostly bispecific [also in the context of IgG4 autoimmune diseases (17)], it is likely that DPPX-IgG4 is not able to divalently bind and cross-link DPPX. While the precise mechanism for downregulation of cell-surfaceexpressed antigen has not yet been demonstrated, it is likely that this is a function of IgG1-3 that causes internalization by divalent binding and cross-linking of antigen. This possibility could be explored by a modification of the experiment using purified IgG subclasses and Fab fragments.
Notably, 10\% of MuSK antibodies are of IgG1 and IgG2 (and very little IgG3) subclass and were pathogenic in vitro (3). MuSK IgG1-3 pathogenicity in vivo could not yet be demonstrated, but can also not yet be excluded, as passive transfer experiments were impaired by the low concentration of MuSK antibodies in the IgG1-3 fraction that were below detection limit in the experimental animals (4). The exact mechanism of pathogenicity for MuSK IgG1-3 is unknown. MuSK-IgG1-3 were able to affect MuSK function in a cellular model of the muscle and neuromuscular synapse, the $\mathrm{C} 2 \mathrm{C} 12$ mouse myotubes. Agrin stimulation leads to MuSK activation and clustering of AChRs, which can be quantified. MuSK antibodies impaired this mechanism and led to reduced clustering of AChRs, and while it is thought that MuSK-IgG4 induce this phenomenon by blocking MuSK-Lrp4 interaction $(2,3)$, it is unclear how MuSK IgG1-3 affected the AChR clustering as they do not interfere with Lrp4-MuSK interaction. Interestingly, MuSK antibodies (both IgG4 and IgG1-3) also disrupted preexisting AChR clusters that were induced by overexpression of Dok7 in C2C12 myotubes [(3) Koneczny/Vincent et al. unpublished data] independent of agrin signaling, which was also found using autoantibodies against Lrp4 derived from an active immunization mouse model (278). An earlier study suggested that Lrp4 is required to make MuSK susceptible to Dok7-induced activation and induction of AChR clustering, presumably with a role for AChR prepatterning before innervation (279). MuSK IgG1-3 could also have an effect on Lrp4, though it is not clear how, or MuSK antibodies may affect Dok7-mediated MuSK activation, perhaps by altering MuSK conformation, MuSK kinase activity and/or preventing binding of Dok7 to MuSK, as observed in CMS with a MuSK mutation (280). It would be interesting to study whether MuSK-IgG1-3 antibodies affect MuSK-Dok7 interaction.

Another potential mechanism of MuSK IgG1-3 is the induction of MuSK endocytosis, which is also suggested to be part of the normal response of MuSK to agrin stimulation (281-283). One study demonstrated that serum from MuSK patients led to the internalization of MuSK in mouse muscle cells using time-lapse microscopy and confocal microscopy (28). Two different studies could not reproduce these findings using different approaches $(2,3)$. However, different patients were tested in these studies, and only a few patients were investigated for endocytosis in all three studies, which is important, as there could be variability in the pathogenic mechanisms in the overall MuSK MG population. In addition, there were technical limitations in the later studies [including my own, as discussed there (3)], hence it is still very possible that MuSK IgG1-3 induce MuSK endocytosis. Further studies are indicated using purified MuSK IgG1-3, MuSK expressed in muscle cells (as transient expression in non-muscle cell environment could affect MuSK endocytosis), and perhaps more appropriate methodology.

In TTP, antibodies of IgG, IgM, and IgA class are present; these may convey pathogenicity by the accelerated clearance of ADAMTS13 from the circulation $(234,284)$. The functional block of ADAMTS13 activity was not restricted to the IgG4 subclass and could also be induced by IgG1 (69). Therefore, the pathogenic mechanism is not linked to the antibody subclass, but rather the 
epitope, as only antibodies that recognize the spacer domain are associated with an inhibitory role (234).

In patients with MN with anti-PLA2R abs, a subclass switch from IgG1 to IgG4 was reported over the course of the disease, with an inverse correlation with C1q involvement (285). It is thus clear that in the initial stage of the disease, IgG1 contributes to pathogenicity by activation of the classical complement pathway (100), which may then at later stages of the disease be replenished or replaced by IgG4 that may be protective, inert, or pathogenic (99).

In pemphigus, IgG1 antibodies against Dsg1 or 3 are present and they may also contribute to the blocking mechanism (221). Additional pathogenic mechanisms in pemphigus were proposed as desmosome disassembly by clustering and endocytosis of Dsg and stimulation of signaling pathways that modulate keratinocyte cell adhesion $(50,51)$. It is thought that multivalent polyclonal Dsg antibodies can cross-link and endocytose Dsg, which leads to Dsg depletion from desmosomes and failed cell adhesion (44-48). However, also monovalent pathogenic anti-Dsg3 antibodies led to a depletion of Dsg3, which suggests that this could also be a mechanism of potentially bispecific (and thus monovalent) Dsg3IgG4 (49).

Taken together, the presence of more than one pathogenic entity in IgG4 autoimmune diseases is quite possible and makes sense, if we consider that a rise of antigen-specific IgG4 in theory could have been an attempt of the immune system to dampen an inappropriate answer to the antigen by a different antibody species. This could also have clinical consequences, as monitoring of different Ig class/IgG subclass-specific autoantibodies may provide a deeper understanding of the autoimmune response, the individual antibody levels or a ratio thereof could be useful as biomarkers for disease progression or the selection of appropriate therapy.

\section{Presence of Multiple Antibodies in Individual Cases}

Two case reports describe the co-occurrence of MuSK MG or TTP with IgG4-RLD $(286,287)$, which brought up the interesting question whether these diseases might be related. The term IgG4 autoimmunity is relatively new and was introduced in 2015 (266). IgG4-RLD [which is also a relatively new term (288)] is at this point considered as a separate clinical entity. IgG4-related disease is not discussed extensively here, an excellent review is suggested for further reading (289) and also a review with focus on IgG4 in IgG4-related disease (290). Due to the rareness of the IgG4 subclass and its involvement in pathology, the possibility exists that IgG4-RLD and IgG4 autoimmunity could be part of the same spectrum. Both diseases are associated with IgG4, and both have a favorable clinical response to B-cell depletion therapy with rituxi$\operatorname{mab}(6,32,78,272-274,289)$. However, IgG4-RLD is defined by the formation of tumefactive lesions in target organs, which is not normally described in IgG4 autoimmunity, and by IgG4+ plasma cell infiltrates and increased serum IgG4 levels. Normal IgG4 concentrations are variable, but are thought to comprise $5 \%$ of total $\operatorname{IgG}(137,138)$. As mean IgG concentrations vary between 7 and $15 \mathrm{~g} / \mathrm{L}$ with a mean around $10 \mathrm{~g} / \mathrm{L}, \mathrm{IgG} 4$ concentrations are expected to be around $0.5 \mathrm{~g} / \mathrm{L}$ (but can rise up to 100 -fold in immune responses). IgG4 concentrations above $1.35 \mathrm{~g} / \mathrm{L}$ are considered as a diagnostic marker for IgG4-RLD (291). In IgG4 autoimmunity, few studies have looked at serum IgG4 levels, but in one study total serum IgG4 was found to be elevated in a small fraction of pemphigus patients (220), which is notable, but only occurred in a minority of patients: three of 27 pemphigus vulgaris patients and three of 16 pemphigus foliaceus patients had IgG4 concentrations above the threshold of $1.35 \mathrm{~g} / \mathrm{L}$ ( or $135 \mathrm{mg} / \mathrm{dL}$ ). In addition, the total $\mathrm{IgG}$ concentrations were reduced in these patients, likely a consequence of immunosuppressive treatment [pemphigus is routinely treated with immunosuppression (292)]. Perhaps the immunosuppressive treatment in combination with an on-going IgG4 autoimmune disease also increased relative IgG4 levels, which would be interesting to study in any IgG4 autoimmune disease using patient serum before and after treatment.

A key characteristic in IgG4 autoimmunity is the presence of antigen-specific autoantibodies of IgG4 subclass with direct pathogenic function. In IgG4-RLD, the role of IgG4 is not well understood, but it is thought that IgG4 may have a blocking, antiinflammatory function. There is indirect evidence for an antigendriven pathogenicity, namely the presence of oligoclonal bands in the CSF of patients and the presence of oligoclonal expansions of somatically hypermutated IgG4+ B-cell clones, but these were not associated with any known autoantigen (293-296). Only a few antigen-specific autoantibodies have been described that are also not consistently found in the disease, and the pathogenicity of these autoantibodies is not known $(297,298)$. Experiments with purified antibodies from patients with a pancreatic form of IgG4-RLD showed that IgG4 blocked pathogenic effects of IgG1 in a passive transfer animal model (299), and a recent study identified Annexin A11 as an antigenic target in some patients with autoimmune pancreatitis. The study findings also suggest that the pathogenic entity may be IgG1 and that IgG4 may be upregulated as an anti-inflammatory measure that blocks pathogenic IgG1 (300). More studies are needed to validate this finding, also for other subtypes of IgG4-RLD. However, the relatively clear pathogenic role of IgG4 in IgG4 autoimmunity and the potentially protective role of IgG4 in IgG4-RLD make it as a consequence not very likely that these disorders are (closely) related.

\section{ETIOLOGY OF IgG4 AUTOIMMUNITY}

The etiology of most autoimmune diseases and thus of most IgG4mediated autoimmune diseases is not known, but there are a few interesting observations that could give a clue to potential factors and mechanisms that may contribute to immunopathogenesis.

\section{Environmental Antigens}

In Europe, MuSK MG frequency correlates with geographical latitude (301), with few cases in northern countries but higher prevalence in the south. This pattern is shared by another IgG4 autoimmune disease, pemphigus (302, 303). The distribution might be coincidental, as epidemiology data of MG in the rest of the northern hemisphere do not reflect the same pattern. Or it could indicate an environmental and/or genetic factor, for example, different availability of an environmental antigen, or different 
climates with different exposure levels to parasites/helminths in the past could have influenced the type 1 hypersensitivity immune answer including the intensity of the IgG4 response. However, the most striking example for environmental antigen-induced autoimmunity comes from fogo selvagem, which is an endemic form of pemphigus that is found mainly in rural areas of Brazil, but also in Colombia and Tunisia $(303,304)$. Here, an association between insect bites and autoimmunity has been found. The bite of the sand fly (Lutzomyia longipalpis) exposes the patient to salivary proteins, specifically LJM11, against which most humans then develop antibodies. While LJM11 itself is a non-pathogenic environmental antigen, mounting an immune response against it is thought to be protective against parasites (specifically Leishmania major) that are also transmitted by the bite of the sand fly (305). Unfortunately, the responding antibodies against the non-pathogenic environmental antigen can also cross-react with self-antigen desmoglein 1 (Dsg1) in individuals with genetic predisposition $(306,307)$. The initial subclinical antibody response is thought to contain IgE, IgG1, and IgM (308-310), then a switch to IgG4 subclass occurs, probably associated with an intramolecular epitope spreading event (311) that is associated with disease onset $(312,313)$. Etiology of autoimmune diseases is rarely as well documented as in the fascinating case of fogo selvagem. It would be interesting to study if a similar mechanism could be at hand in other IgG4-mediated diseases. A test for antigen-specific IgE in IgG4-associated diseases could give first indications if this was the case. Indeed, a potential link to allergy recently emerged for a different IgG4-associated disease, IgG4-RLD. An association of IgG4-RLD with a history of allergy was already suspected (314), then a polyclonal response to multiple non-infectious environmental antigens was discovered (315) and a rise in IgE and eosinophil levels was found to predict relapse and to have potential use as diagnostic and prognostic biomarkers (316).

\section{Infection}

Several different (potential) IgG4 autoimmune diseases may have a link to infection, generally thought to be conveyed by molecular mimicry, where antibodies against pathogens cross-react against self-antigen. The autoreactive B-cells in pemphigus showed a shared VH1-46 gene usage, and these were associated with few somatic mutations, which suggests that naïve B-cells that use VH1-46 genes are prone to react against Dsg3 (55). VH1-46 $\mathrm{B}$ cells are also associated with an increased reaction toward rotavirus capsid protein VP6 and may thus confer a protection toward infection, highlighting the potential for rare cross-reactive clones to trigger the onset of pemphigus autoimmunity $(317,318)$. In one of two known CIDP patient with Caspr1-IgG4, disease onset was 10 days after preceding virus infection (common cold) (124). Patients with DPPX encephalitis usually experience severe prodromal symptoms of diarrhea and weight loss (median $20 \mathrm{~kg}$ ), sometimes accompanied by headache or mood disorder, then within a few months the patients develop a range of neurological symptoms $(125,127,128)$. DPPX is strongly expressed in not only the myenteric plexus, a mesh of neurons in the gastrointestinal tract, but also the hippocampus, cerebellum, and striatum. The curious shift in symptoms is reminiscent of a gastrointestinal infection that leads to the mounting of an autoimmune attack against the myenteric plexus via molecular mimicry or bystander attack mechanisms, as seen, e.g., in Campylobacter jejuni infection that causes the Guillain-Barré syndrome [reviewed, e.g., by Ref. (319)]. So far, no pathogen was found to be associated with the prodromal symptoms in DPPX-encephalitis, and it is also possible that this shift may have different causality, but it is an intriguing possibility to keep in mind.

In case of PLA2R antibody-positive MN, infection and molecular mimicry were proposed to potentially contribute to immunopathogenesis, as there is partial homology between PLA2R peptides and bacterial cell wall enzymes of Clostridium species (101, 320, 321). A link between infection and Goodpasture's disease with antibodies against non-collagenous domain 1 of $\alpha 3$ chain of type IV collagen was also described $(322,323)$. One case of TTP was associated with Epstein-Barr virus reactivation (324), another case disease onset was associated with an influenza A infection (325) and another with dengue virus infection (326).

\section{Vaccination}

There are a few cases of TTP onset or relapse after vaccination (327-329). This is interesting, as a related disease, immune thrombocytopenic purpura, which has antibodies against platelets, is also associated with vaccination (330).

\section{Malignancy}

Overexpression of antigen by tumors can trigger an autoimmune response. THSD7A-positive $\mathrm{MN}$ is associated with malignancy, as THSD7A itself may also play a role in certain cancers (331) and specifically two cases were described, one with gallbladder carcinoma, one with endometrial cancer, where THSD7A was overexpressed in the tumor and taken up by follicular dendritic cells in a regional lymph node $(106,113,115,116)$.

\section{Summary and Conclusion}

In recent years, many IgG4 autoantibodies were discovered, particularly against neuronal targets. By now, 14 different antigen targets have been described and suggested to play a causative role in "IgG4 autoimmunity" (266). Using a modified version of the Witebsky postulates to identify IgG4 autoimmune diseases with proven pathogenicity of IgG4 autoantibodies, the diseases were classified into three categories: class I with proven pathogenicity of IgG4 autoantibodies (including TTP with ADAMTS13 antibodies, pemphigus vulgaris with anti-Dsg3 antibodies, pemphigus foliaceus with anti-Dsg1 antibodies, MuSK MG and CIDP with anti-CNTN1 antibodies), class II where pathogenicity of IgG4 is highly suspected (anti-Lgi1 - and Caspr2-associated encephalitis/ Morvan's syndrome, CIDP with anti-neurofascin 155 antibodies, and MN with anti-PLA2R or anti-THSD7A antibodies), and finally class III with diseases where IgG4 pathogenicity has not been studied extensively yet (anti-Caspr1-associated CIDP and Goodpasture syndrome with IgG4 antibodies against Collagen IV alpha3NCI) or that have a main pathogenic mechanism that relies on divalent binding, cross-linking and endocytosis of antigen (Iglon5 parasomnia and anti-DPPX encephalitis). Class II and III diseases require further investigation to determine the pathogenicity of IgG4, ideally by passive transfer experiments with purified patient IgG4. Evaluation of the diseases suggests that IgG4 is 
mainly pathogenic by blocking protein-protein interaction, but that in many cases non-IgG4 autoantibodies are present that may contribute to pathogenicity by other mechanisms, in many cases activation of classical complement is suspected. This may have clinical consequences for treatment decisions. The possibility of an association between IgG4 autoimmunity and IgG4-RLD was discussed but found unlikely.

\section{AUTHOR CONTRIBUTIONS}

The author confirms being the sole contributor of this work and approved it for publication.

\section{REFERENCES}

1. Ludwig RJ, Vanhoorelbeke K, Leypoldt F, Kaya Z, Bieber K, McLachlan SM, et al. Mechanisms of autoantibody-induced pathology. Front Immunol (2017) 8:603. doi:10.3389/fimmu.2017.00603

2. Huijbers MG, Zhang W, Klooster R, Niks EH, Friese MB, Straasheijm KR, et al. MuSK IgG4 autoantibodies cause myasthenia gravis by inhibiting binding between MuSK and Lrp4. Proc Natl Acad Sci U S A (2013) 110(51):20783-8. doi:10.1073/pnas.1313944110

3. Koneczny I, Cossins J, Waters P, Beeson D, Vincent A. MuSK myasthenia gravis IgG4 disrupts the interaction of LRP4 with MuSK but both IgG4 and IgG1-3 can disperse preformed agrin-independent AChR clusters. PLoS One (2013) 8(11):e80695. doi:10.1371/journal.pone.0080695

4. Klooster R, Plomp JJ, Huijbers MG, Niks EH, Straasheijm KR, Detmers FJ, et al. Muscle-specific kinase myasthenia gravis IgG4 autoantibodies cause severe neuromuscular junction dysfunction in mice. Brain (2012) 135(Pt 4):1081-101. doi:10.1093/brain/aws025

5. Mori S, Kubo S, Akiyoshi T, Yamada S, Miyazaki T, Hotta H, et al. Antibodies against muscle-specific kinase impair both presynaptic and postsynaptic functions in a murine model of myasthenia gravis. Am J Pathol (2012) 180(2):798-810. doi:10.1016/j.ajpath.2011.10.031

6. Hehir MK, Hobson-Webb LD, Benatar M, Barnett C, Silvestri NJ, Howard JF $\mathrm{Jr}$, et al. Rituximab as treatment for anti-MuSK myasthenia gravis: multicenter blinded prospective review. Neurology (2017) 89(10):1069-77. doi:10.1212/ WNL.0000000000004341

7. Keung B, Robeson KR, Dicapua DB, Rosen JB, O'Connor KC, Goldstein JM, et al. Long-term benefit of rituximab in MuSK autoantibody myasthenia gravis patients. J Neurol Neurosurg Psychiatry (2013) 84(12):1407-9. doi:10.1136/jnnp-2012-303664

8. Diaz-Manera J, Martinez-Hernandez E, Querol L, Klooster R, Rojas-Garcia $\mathrm{R}$, Suarez-Calvet $\mathrm{X}$, et al. Long-lasting treatment effect of rituximab in MuSK myasthenia. Neurology (2012) 78(3):189-93. doi:10.1212/ WNL.0b013e3182407982

9. Evoli A, Padua L. Diagnosis and therapy of myasthenia gravis with antibodies to muscle-specific kinase. Autoimmun Rev (2013) 12(9):931-5. doi:10.1016/j. autrev.2013.03.004

10. Nowak RJ, DiCapua DB, Zebardast N, Goldstein JM. Response of patients with refractory myasthenia gravis to rituximab: a retrospective study. Ther Adv Neurol Disord (2011) 4(5):259-66. doi:10.1177/1756285611411503

11. Thakre M, Inshasi J, Marashi M. Rituximab in refractory MuSK antibody myasthenia gravis. J Neurol (2007) 254(7):968-9. doi:10.1007/ s00415-006-0442-2

12. Hain B, Jordan K, Deschauer M, Zierz S. Successful treatment of MuSK antibody-positive myasthenia gravis with rituximab. Muscle Nerve (2006) 33(4):575-80. doi:10.1002/mus.20479

13. Evoli A, Bianchi MR, Riso R, Minicuci GM, Batocchi AP, Servidei S, et al. Response to therapy in myasthenia gravis with anti-MuSK antibodies. Ann N Y Acad Sci (2008) 1132:76-83. doi:10.1196/annals.1405.012

14. Niks EH, Kuks JB, Roep BO, Haasnoot GW, Verduijn W, Ballieux BE, et al. Strong association of MuSK antibody-positive myasthenia gravis and HLA-DR14-DQ5. Neurology (2006) 66(11):1772-4. doi:10.1212/01. wnl.0000218159.79769.5c

\section{ACKNOWLEDGMENTS}

I would like to express my deepest gratitude to Jan Bauer, Laurence Beck, Aimee Payne, Mårten Segelmark, Donald Siegel, and Angela Vincent (in alphabetical order) for their helpful suggestions and/ or scientific advice. Especially helpful was the thorough review of the manuscript by Jan Bauer, Laurence Beck, and Aimee Payne, which has greatly improved its quality. Furthermore, I want to thank Theo Rispens that I could base Figure 1A partly on one of his previously published figures. IK was funded by an ErwinSchrödinger fellowship by the Austrian Science Fund (FWF): Project number J3545-B13.

15. Bartoccioni E, Scuderi F, Augugliaro A, Chiatamone Ranieri S, Sauchelli D, Alboino P, et al. HLA class II allele analysis in MuSK-positive myasthenia gravis suggests a role for DQ5. Neurology (2009) 72(2):195-7. doi:10.1212/01. wnl.0000339103.08830.86

16. McConville J, Farrugia ME, Beeson D, Kishore U, Metcalfe R, Newsom-Davis J, et al. Detection and characterization of MuSK antibodies in seronegative myasthenia gravis. Ann Neurol (2004) 55(4):580-4. doi:10.1002/ana.20061

17. Koneczny I, Stevens JA, De Rosa A, Huda S, Huijbers MG, Saxena A, et al. IgG4 autoantibodies against muscle-specific kinase undergo Fab-arm exchange in myasthenia gravis patients. J Autoimmun (2017) 77:104-15. doi:10.1016/j.jaut.2016.11.005

18. Otsuka K, Ito M, Ohkawara B, Masuda A, Kawakami Y, Sahashi K, et al. Collagen Q and anti-MuSK autoantibody competitively suppress agrin/ LRP4/MuSK signaling. Sci Rep (2015) 5:13928. doi:10.1038/srep13928

19. Mori S, Yamada S, Kubo S, Chen J, Matsuda S, Shudou M, et al. Divalent and monovalent autoantibodies cause dysfunction of MuSK by distinct mechanisms in a rabbit model of myasthenia gravis. J Neuroimmunol (2012) 244(1-2):1-7. doi:10.1016/j.jneuroim.2011.12.005

20. Shigemoto K, Kubo S, Maruyama N, Hato N, Yamada H, Jie C, et al. Induction of myasthenia by immunization against muscle-specific kinase. J Clin Invest (2006) 116(4):1016-24. doi:10.1172/JCI21545

21. Morsch M, Reddel SW, Ghazanfari N, Toyka KV, Phillips WD. Muscle specific kinase autoantibodies cause synaptic failure through progressive wastage of postsynaptic acetylcholine receptors. Exp Neurol (2012) 237(2):286-95. doi:10.1016/j.expneurol.2012.06.034

22. Selcen D, Fukuda T, Shen XM, Engel AG. Are MuSK antibodies the primary cause of myasthenic symptoms? Neurology (2004) 62(11):1945-50. doi:10.1212/01.WNL.0000128048.23930.1D

23. Shiraishi H, Motomura M, Yoshimura T, Fukudome T, Fukuda T, Nakao $\mathrm{Y}$, et al. Acetylcholine receptors loss and postsynaptic damage in MuSK antibody-positive myasthenia gravis. Ann Neurol (2005) 57(2):289-93. doi:10.1002/ana.20341

24. Farrugia ME, Kennett RP, Newsom-Davis J, Hilton-Jones D, Vincent A. Single-fiber electromyography in limb and facial muscles in muscle-specific kinase antibody and acetylcholine receptor antibody myasthenia gravis. Muscle Nerve (2006) 33(4):568-70. doi:10.1002/mus.20491

25. Cole RN, Reddel SW, Gervasio OL, Phillips WD. Anti-MuSK patient antibodies disrupt the mouse neuromuscular junction. Ann Neurol (2008) 63(6):782-9. doi:10.1002/ana.21371

26. Viegas S, Jacobson L, Waters P, Cossins J, Jacob S, Leite MI, et al. Passive and active immunization models of MuSK-Ab positive myasthenia: electrophysiological evidence for pre and postsynaptic defects. Exp Neurol (2012) 234(2):506-12. doi:10.1016/j.expneurol.2012.01.025

27. Hoch W, McConville J, Helms S, Newsom-Davis J, Melms A, Vincent A. Auto-antibodies to the receptor tyrosine kinase MuSK in patients with myasthenia gravis without acetylcholine receptor antibodies. Nat Med (2001) 7(3):365-8. doi:10.1038/85520

28. Cole RN, Ghazanfari N, Ngo ST, Gervasio OL, Reddel SW, Phillips WD. Patient autoantibodies deplete postsynaptic muscle-specific kinase leading to disassembly of the ACh receptor scaffold and myasthenia gravis in mice. J Physiol (2010) 588(Pt 17):3217-29. doi:10.1113/ jphysiol.2010.190298 
29. Miura Y, Devaux JJ, Fukami Y, Manso C, Belghazi M, Wong AH, et al. Contactin 1 IgG4 associates to chronic inflammatory demyelinating polyneuropathy with sensory ataxia. Brain (2015) 138(Pt 6):1484-91. doi:10.1093/brain/awv054

30. Labasque M, Hivert B, Nogales-Gadea G, Querol L, Illa I, Faivre-Sarrailh C. Specific contactin $\mathrm{N}$-glycans are implicated in neurofascin binding and autoimmune targeting in peripheral neuropathies. J Biol Chem (2014) 289(11):7907-18. doi:10.1074/jbc.M113.528489

31. Manso C, Querol L, Mekaouche M, Illa I, Devaux JJ. Contactin-1 IgG4 antibodies cause paranode dismantling and conduction defects. Brain (2016) 139(Pt 6):1700-12. doi:10.1093/brain/aww062

32. Querol L, Rojas-Garcia R, Diaz-Manera J, Barcena J, Pardo J, Ortega-Moreno $\mathrm{A}$, et al. Rituximab in treatment-resistant CIDP with antibodies against paranodal proteins. Neurol Neuroimmunol Neuroinflamm (2015) 2(5):e149. doi:10.1212/NXI.0000000000000149

33. Mathey EK, Garg N, Park SB, Nguyen T, Baker S, Yuki N, et al. Autoantibody responses to nodal and paranodal antigens in chronic inflammatory neuropathies. J Neuroimmunol (2017) 309:41-6. doi:10.1016/j.jneuroim.2017.05.002

34. Doppler K, Appeltshauser L, Wilhelmi K, Villmann C, Dib-Hajj SD, Waxman SG, et al. Destruction of paranodal architecture in inflammatory neuropathy with anti-contactin-1 autoantibodies. J Neurol Neurosurg Psychiatry (2015) 86(7):720-8. doi:10.1136/jnnp-2014-309916

35. Querol L, Nogales-Gadea G, Rojas-Garcia R, Martinez-Hernandez E, DiazManera J, Suarez-Calvet X, et al. Antibodies to contactin-1 in chronic inflammatory demyelinating polyneuropathy. Ann Neurol (2013) 73(3):370-80. doi:10.1002/ana.23794

36. Futei $Y$, Amagai M, Ishii K, Kuroda-Kinoshita K, Ohya K, Nishikawa T. Predominant IgG4 subclass in autoantibodies of pemphigus vulgaris and foliaceus. J Dermatol Sci (2001) 26(1):55-61. doi:10.1016/S0923-1811(00)00158-4

37. Rock B, Martins CR, Theofilopoulos AN, Balderas RS, Anhalt GJ, Labib RS, et al. The pathogenic effect of IgG4 autoantibodies in endemic pemphigus foliaceus (fogo selvagem). N Engl J Med (1989) 320(22):1463-9. doi:10.1056/ NEJM198906013202206

38. Stanley JR, Amagai M. Pemphigus, bullous impetigo, and the staphylococcal scalded-skin syndrome. N Engl J Med (2006) 355(17):1800-10. doi:10.1056/ NEJMra061111

39. Amagai M. Desmoglein as a target in autoimmunity and infection. J Am Acad Dermatol (2003) 48(2):244-52. doi:10.1067/mjd.2003.7

40. Boggon TJ, Murray J, Chappuis-Flament S, Wong E, Gumbiner BM, Shapiro L. C-cadherin ectodomain structure and implications for cell adhesion mechanisms. Science (2002) 296(5571):1308-13. doi:10.1126/science.1071559

41. Harrison OJ, Brasch J, Lasso G, Katsamba PS, Ahlsen G, Honig B, et al. Structural basis of adhesive binding by desmocollins and desmogleins. Proc Natl Acad Sci U S A (2016) 113(26):7160-5. doi:10.1073/pnas.1606272113

42. Tsunoda K, Ota T, Aoki M, Yamada T, Nagai T, Nakagawa T, et al. Induction of pemphigus phenotype by a mouse monoclonal antibody against the amino-terminal adhesive interface of desmoglein 3. JImmunol (2003) 170(4):2170-8. doi:10.4049/jimmunol.170.4.2170

43. Di Zenzo G, Di Lullo G, Corti D, Calabresi V, Sinistro A, Vanzetta F, et al. Pemphigus autoantibodies generated through somatic mutations target the desmoglein-3 cis-interface. J Clin Invest (2012) 122(10):3781-90. doi:10.1172/JCI64413

44. Oktarina DA, van der Wier G, Diercks GF, Jonkman MF, Pas HH. IgGinduced clustering of desmogleins 1 and 3 in skin of patients with pemphigus fits with the desmoglein nonassembly depletion hypothesis. $\mathrm{Br}$ J Dermatol (2011) 165(3):552-62. doi:10.1111/j.1365-2133.2011.10463.x

45. van der Wier G, Pas HH, Kramer D, Diercks GFH, Jonkman MF. Smaller desmosomes are seen in the skin of pemphigus patients with anti-desmoglein 1 antibodies but not in patients with anti-desmoglein 3 antibodies. J Invest Dermatol (2014) 134(8):2287-90. doi:10.1038/jid.2014.140

46. Aoyama Y, Kitajima Y. Pemphigus vulgaris-IgG causes a rapid depletion of desmoglein 3 (Dsg3) from the Triton X-100 soluble pools, leading to the formation of Dsg3-depleted desmosomes in a human squamous carcinoma cell line, DJM-1 cells. J Invest Dermatol (1999) 112(1):67-71. doi:10.1046/j.1523-1747.1999.00463.x

47. Jennings JM, Tucker DK, Kottke MD, Saito M, Delva E, Hanakawa Y, et al. Desmosome disassembly in response to pemphigus vulgaris IgG occurs in distinct phases and can be reversed by expression of exogenous Dsg3.J Invest Dermatol (2011) 131(3):706-18. doi:10.1038/jid.2010.389
48. Stahley SN, Saito M, Faundez V, Koval M, Mattheyses AL, Kowalczyk AP. Desmosome assembly and disassembly are membrane raft-dependent. PLoS One (2014) 9(1):e87809. doi:10.1371/journal.pone.0087809

49. Mao X, Choi EJ, Payne AS. Disruption of desmosome assembly by monovalent human pemphigus vulgaris monoclonal antibodies. J Invest Dermatol (2009) 129(4):908-18. doi:10.1038/jid.2008.339

50. Calkins CC, Setzer SV, Jennings JM, Summers S, Tsunoda K, Amagai M, et al. Desmoglein endocytosis and desmosome disassembly are coordinated responses to pemphigus autoantibodies. J Biol Chem (2006) 281(11):7623-34. doi:10.1074/jbc.M512447200

51. Saito M, Stahley SN, Caughman CY, Mao X, Tucker DK, Payne AS, et al. Signaling dependent and independent mechanisms in pemphigus vulgaris blister formation. PLoS One (2012) 7(12):e50696. doi:10.1371/journal. pone. 0050696

52. Kasperkiewicz M, Ellebrecht CT, Takahashi H, Yamagami J, Zillikens D, Payne AS, et al. Pemphigus. Nat Rev Dis Primers (2017) 3:17026. doi:10.1038/ nrdp.2017.26

53. Yamagami J, Payne AS, Kacir S, Ishii K, Siegel DL, Stanley JR. Homologous regions of autoantibody heavy chain complementarity-determining region 3 (H-CDR3) in patients with pemphigus cause pathogenicity. J Clin Invest (2010) 120(11):4111-7. doi:10.1172/JCI44425

54. Zhao CY, Chiang YZ, Murrell DF. Neonatal autoimmune blistering disease: a systematic review. Pediatr Dermatol (2016) 33(4):367-74. doi:10.1111/ pde. 12859

55. Cho MJ, Lo AS, Mao X, Nagler AR, Ellebrecht CT, Mukherjee EM, et al. Shared VH1-46 gene usage by pemphigus vulgaris autoantibodies indicates common humoral immune responses among patients. Nat Commun (2014) 5:4167. doi:10.1038/ncomms5167

56. Joly P, Maho-Vaillant M, Prost-Squarcioni C, Hebert V, Houivet E, Calbo $S$, et al. First-line rituximab combined with short-term prednisone versus prednisone alone for the treatment of pemphigus (Ritux 3): a prospective, multicentre, parallel-group, open-label randomised trial. Lancet (2017) 389(10083):2031-40. doi:10.1016/S0140-6736(17)30070-3

57. Payne AS, Ishii K, Kacir S, Lin C, Li H, Hanakawa Y, et al. Genetic and functional characterization of human pemphigus vulgaris monoclonal autoantibodies isolated by phage display. J Clin Invest (2005) 115(4):888-99. doi:10.1172/JCI24185

58. Casina VC, Hu W, Mao JH, Lu RN, Hanby HA, Pickens B, et al. Highresolution epitope mapping by HX MS reveals the pathogenic mechanism and a possible therapy for autoimmune TTP syndrome. Proc Natl Acad Sci U $S$ A (2015) 112(31):9620-5. doi:10.1073/pnas.1512561112

59. Ostertag EM, Bdeir K, Kacir S, Thiboutot M, Gulendran G, Yunk L, et al. ADAMTS13 autoantibodies cloned from patients with acquired thrombotic thrombocytopenic purpura: 2. Pathogenicity in an animal model. Transfusion (2016) 56(7):1775-85. doi:10.1111/trf.13583

60. Tsai HM, Lian EC. Antibodies to von Willebrand factor-cleaving protease in acute thrombotic thrombocytopenic purpura. N Engl J Med (1998) 339(22):1585-94. doi:10.1056/NEJM199811263392203

61. Ostertag EM, Kacir S, Thiboutot M, Gulendran G, Zheng XL, Cines DB, et al. ADAMTS13 autoantibodies cloned from patients with acquired thrombotic thrombocytopenic purpura: 1 . Structural and functional characterization in vitro. Transfusion (2016) 56(7):1763-74. doi:10.1111/trf.13584

62. FerrariS, Mudde GC, Rieger M, Veyradier A, Kremer Hovinga JA, Scheiflinger F. IgG subclass distribution of anti-ADAMTS13 antibodies in patients with acquired thrombotic thrombocytopenic purpura. J Thromb Haemost (2009) 7(10):1703-10. doi:10.1111/j.1538-7836.2009.03568.x

63. Nakao H, Ishiguro A, Ikoma N, Nishi K, Su C, Nakadate H, et al. Acquired idiopathic thrombotic thrombocytopenic purpura successfully treated with intravenous immunoglobulin and glucocorticoid: a case report. Medicine (Baltimore) (2017) 96(14):e6547. doi:10.1097/MD.0000000000006547

64. Coppo P, Busson M, Veyradier A, Wynckel A, Poullin P, Azoulay E, et al. HLA-DRB1*11: a strong risk factor for acquired severe ADAMTS13 deficiency-related idiopathic thrombotic thrombocytopenic purpura in Caucasians. J Thromb Haemost (2010) 8(4):856-9. doi:10.1111/j.1538-7836.2010.03772.x

65. Sinkovits G, Szilagyi A, Farkas P, Inotai D, Szilvasi A, Tordai A, et al. The role of human leukocyte antigen DRB1-DQB1 haplotypes in the susceptibility to acquired idiopathic thrombotic thrombocytopenic purpura. Hum Immunol (2017) 78(2):80-7. doi:10.1016/j.humimm.2016.11.005 
66. Ferrari S, Palavra K, Gruber B, Kremer Hovinga JA, Knobl P, Caron C, et al. Persistence of circulating ADAMTS13-specific immune complexes in patients with acquired thrombotic thrombocytopenic purpura. Haematologica (2014) 99(4):779-87. doi:10.3324/haematol.2013.094151

67. Feys HB, Roodt J, Vandeputte N, Pareyn I, Lamprecht S, van Rensburg WJ, et al. Thrombotic thrombocytopenic purpura directly linked with ADAMTS13 inhibition in the baboon (Papio ursinus). Blood (2010) 116(12):2005-10. doi:10.1182/blood-2010-04-280479

68. Luken BM, Turenhout EA, Hulstein JJ, Van Mourik JA, Fijnheer R, Voorberg J. The spacer domain of ADAMTS13 contains a major binding site for antibodies in patients with thrombotic thrombocytopenic purpura. Thromb Haemost (2005) 93(2):267-74. doi:10.1160/TH04-05-0301

69. Schaller M, Vogel M, Kentouche K, Lammle B, Kremer Hovinga JA. The splenic autoimmune response to ADAMTS13 in thrombotic thrombocytopenic purpura contains recurrent antigen-binding CDR3 motifs. Blood (2014) 124(23):3469-79. doi:10.1182/blood-2014-04-561142

70. Ohkawa T, Fukata Y, Yamasaki M, Miyazaki T, Yokoi N, Takashima H, et al. Autoantibodies to epilepsy-related LGI1 in limbic encephalitis neutralize LGI1-ADAM22 interaction and reduce synaptic AMPA receptors. J Neurosci (2013) 33(46):18161-74. doi:10.1523/JNEUROSCI.3506-13.2013

71. Irani SR, Pettingill P, Kleopa KA, Schiza N, Waters P, Mazia C, et al. Morvan syndrome: clinical and serological observations in 29 cases. Ann Neurol (2012) 72(2):241-55. doi:10.1002/ana.23577

72. Arino H, Armangue T, Petit-Pedrol M, Sabater L, Martinez-Hernandez E, Hara M, et al. Anti-LGI1-associated cognitive impairment: presentation and long-term outcome. Neurology (2016) 87(8):759-65. doi:10.1212/ WNL.0000000000003009

73. Bien CG, Vincent A, Barnett MH, Becker AJ, Blumcke I, Graus F, et al. Immunopathology of autoantibody-associated encephalitides: clues for pathogenesis. Brain (2012) 135(Pt 5):1622-38. doi:10.1093/brain/aws082

74. Lalic T, Pettingill P, Vincent A, Capogna M. Human limbic encephalitis serum enhances hippocampal mossy fiber-CA3 pyramidal cell synaptic transmission. Epilepsia (2011) 52(1):121-31. doi:10.1111/j.1528-1167.2010.02756.X

75. van Sonderen A, Roelen DL, Stoop JA, Verdijk RM, Haasnoot GW, Thijs RD, et al. Anti-LGI1 encephalitis is strongly associated with HLA-DR7 and HLADRB4. Ann Neurol (2017) 81(2):193-8. doi:10.1002/ana.24858

76. Kim TJ, Lee ST, Moon J, Sunwoo JS, Byun JI, Lim JA, et al. Anti-LGI1 encephalitis is associated with unique HLA subtypes. Ann Neurol (2017) 81(2):183-92. doi:10.1002/ana.24860

77. van Sonderen A, Thijs RD, Coenders EC, Jiskoot LC, Sanchez E, de Bruijn MA, et al. Anti-LGI1 encephalitis: clinical syndrome and long-term follow-up. Neurology (2016) 87(14):1449-56. doi:10.1212/WNL.0000000000003173

78. Irani SR, Gelfand JM, Bettcher BM, Singhal NS, Geschwind MD. Effect of rituximab in patients with leucine-rich, glioma-inactivated 1 antibody-associated encephalopathy. JAMA Neurol (2014) 71(7):896-900. doi:10.1001/ jamaneurol.2014.463

79. Ng JK, Malotka J, Kawakami N, Derfuss T, Khademi M, Olsson T, et al. Neurofascin as a target for autoantibodies in peripheral neuropathies. Neurology (2012) 79(23):2241-8. doi:10.1212/WNL.0b013e31827689ad

80. Querol L, Devaux J, Rojas-Garcia R, Illa I. Autoantibodies in chronic inflammatory neuropathies: diagnostic and therapeutic implications. Nat Rev Neurol (2017) 13(9):533-47. doi:10.1038/nrneurol.2017.84

81. Devaux JJ, Miura Y, Fukami Y, Inoue T, Manso C, Belghazi M, et al. Neurofascin-155 IgG4 in chronic inflammatory demyelinating polyneuropathy. Neurology (2016) 86(9):800-7. doi:10.1212/WNL.0000000000002418

82. Shimizu M, Koda T, Nakatsuji Y, Ogata H, Kira JI, Mochizuki H. A case of anti-neurofascin 155 antibody-positive combined central and peripheral demyelination successfully treated with plasma exchange. Rinsho Shinkeigaku (2017) 57(1):41-4. doi:10.5692/clinicalneurol.cn-000964

83. Querol L, Nogales-Gadea G, Rojas-Garcia R, Diaz-Manera J, Pardo J, OrtegaMoreno A, et al. Neurofascin IgG4 antibodies in CIDP associate with disabling tremor and poor response to IVIg. Neurology (2014) 82(10):879-86. doi:10.1212/WNL.0000000000000205

84. Kadoya M, Kaida K, Koike H, Takazaki H, Ogata H, Moriguchi K, et al. IgG4 anti-neurofascin155 antibodies in chronic inflammatory demyelinating polyradiculoneuropathy: clinical significance and diagnostic utility of a conventional assay. J Neuroimmunol (2016) 301:16-22. doi:10.1016/j. jneuroim.2016.10.013
85. Ogata H, Yamasaki R, Hiwatashi A, Oka N, Kawamura N, Matsuse D, et al. Characterization of IgG4 anti-neurofascin 155 antibody-positive polyneuropathy. Ann Clin Transl Neurol (2015) 2(10):960-71. doi:10.1002/acn3.248

86. Olsen AL, Lai Y, Dalmau J, Scherer SS, Lancaster E. Caspr2 autoantibodies target multiple epitopes. Neurol Neuroimmunol Neuroinflmm (2015) 2(4):e127. doi:10.1212/NXI.0000000000000127

87. Pinatel D, Hivert B, Boucraut J, Saint-Martin M, Rogemond V, Zoupi L, et al. Inhibitory axons are targeted in hippocampal cell culture by anti-Caspr2 autoantibodies associated with limbic encephalitis. Front Cell Neurosci (2015) 9:265. doi:10.3389/fncel.2015.00265

88. van Sonderen A, Arino H, Petit-Pedrol M, Leypoldt F, Kortvelyessy P, Wandinger KP, et al. The clinical spectrum of Caspr2 antibody-associated disease. Neurology (2016) 87(5):521-8. doi:10.1212/WNL.0000000000002917

89. Kortvelyessy P, Bauer J, Stoppel CM, Bruck W, Gerth I, Vielhaber S, et al. Complement-associated neuronal loss in a patient with CASPR2 antibody-associated encephalitis. Neurol Neuroimmunol Neuroinflamm (2015) 2(2):e75. doi:10.1212/NXI.0000000000000075

90. Sunwoo JS, Lee ST, Byun JI, Moon J, Shin JW, Jeong DE, et al. Clinical manifestations of patients with CASPR2 antibodies. J Neuroimmunol (2015) 281:17-22. doi:10.1016/j.jneuroim.2015.03.005

91. Lancaster E, Huijbers MG, Bar V, Boronat A, Wong A, Martinez-Hernandez $\mathrm{E}$, et al. Investigations of caspr2, an autoantigen of encephalitis and neuromyotonia. Ann Neurol (2011) 69(2):303-11. doi:10.1002/ana.22297

92. Bien CG, Mirzadjanova Z, Baumgartner C, Onugoren MD, Grunwald T, Holtkamp M, et al. Anti-contactin-associated protein-2 encephalitis: relevance of antibody titres, presentation and outcome. Eur J Neurol (2017) 24(1):175-86. doi:10.1111/ene.13180

93. Irani SR, Alexander S, Waters P, Kleopa KA, Pettingill P, Zuliani L, et al. Antibodies to Kv1 potassium channel-complex proteins leucine-rich, glioma inactivated 1 protein and contactin-associated protein-2 in limbic encephalitis, Morvan's syndrome and acquired neuromyotonia. Brain (2010) 133(9):2734-48. doi:10.1093/brain/awq213

94. Brimberg L, Mader S, Jeganathan V, Berlin R, Coleman TR, Gregersen PK, et al. Caspr2-reactive antibody cloned from a mother of an ASD child mediates an ASD-like phenotype in mice. Mol Psychiatry (2016) 21(12):1663-71. doi:10.1038/mp.2016.165

95. Sundal C, Vedeler C, Miletic H, Andersen O. Morvan syndrome with Caspr2 antibodies. Clinical and autopsy report. J Neurol Sci (2017) 372:453-5. doi:10.1016/j.jns.2016.10.046

96. Balint B, Regula JU, Jarius S, Wildemann B. Caspr2 antibodies in limbic encephalitis with cerebellar ataxia, dyskinesias and myoclonus. J Neurol Sci (2013) 327(1-2):73-4. doi:10.1016/j.jns.2013.01.040

97. Beck LH Jr, Salant DJ. Membranous nephropathy: from models to man. J Clin Invest (2014) 124(6):2307-14. doi:10.1172/JCI72270

98. Yang Y, Wang C, Jin L, He F, Li C, Gao Q, et al. IgG4 anti-phospholipase A2 receptor might activate lectin and alternative complement pathway meanwhile in idiopathic membranous nephropathy: an inspiration from a cross-sectional study. Immunol Res (2016) 64(4):919-30. doi:10.1007/ s12026-016-8790-1

99. Segawa Y, Hisano S, Matsushita M, Fujita T, Hirose S, Takeshita M, et al. IgG subclasses and complement pathway in segmental and global membranous nephropathy. Pediatr Nephrol (2010) 25(6):1091-9. doi:10.1007/ s00467-009-1439-8

100. Kanigicherla D, Gummadova J, McKenzie EA, Roberts SA, Harris S, Nikam $M$, et al. Anti-PLA2R antibodies measured by ELISA predict long-term outcome in a prevalent population of patients with idiopathic membranous nephropathy. Kidney Int (2013) 83(5):940-8. doi:10.1038/ki.2012.486

101. Fresquet M, Jowitt TA, Gummadova J, Collins R, O'Cualain R, McKenzie EA, et al. Identification of a major epitope recognized by PLA2R autoantibodies in primary membranous nephropathy. J Am Soc Nephrol (2015) 26(2):302-13. doi:10.1681/ASN.2014050502

102. Kao L, Lam V, Waldman M, Glassock RJ, Zhu Q. Identification of the immunodominant epitope region in phospholipase A2 receptor-mediating autoantibody binding in idiopathic membranous nephropathy. J Am Soc Nephrol (2015) 26(2):291-301. doi:10.1681/ASN.2013121315

103. Lhotta K, Wurzner R, Konig P. Glomerular deposition of mannose-binding lectin in human glomerulonephritis. Nephrol Dial Transplant (1999) 14(4):881-6. doi:10.1093/ndt/14.4.881 
104. Lv J, Hou W, Zhou X, Liu G, Zhou F, Zhao N, et al. Interaction between PLA2R1 and HLA-DQA1 variants associates with anti-PLA2R antibodies and membranous nephropathy. J Am Soc Nephrol (2013) 24(8):1323-9. doi:10.1681/ASN.2012080771

105. Muller-Deile J, Schiffer L, Hiss M, Haller H, Schiffer M. A new rescue regimen with plasma exchange and rituximab in high-risk membranous glomerulonephritis. Eur J Clin Invest (2015) 45(12):1260-9. doi:10.1111/ eci. 12545

106. Beck LH Jr. PLA2R and THSD7A: disparate paths to the same disease? J Am Soc Nephrol (2017) 28(9):2579-89. doi:10.1681/ASN.2017020178

107. Borza DB. Alternative pathway dysregulation and the conundrum of complement activation by IgG4 immune complexes in membranous nephropathy. Front Immunol (2016) 7:157. doi:10.3389/fimmu.2016.00157

108. Ma H, Beck LJ, Salant D. Membranous nephropathy-associated anti-phospholipase A2 receptor IgG4 autoantibodies activate the lectin complement pathway (abstract). J Am Soc Nephrol (2011) 22:62A.

109. Hayashi N, Okada K, Matsui Y, Fujimoto K, Adachi H, Yamaya H, et al. Glomerular mannose-binding lectin deposition in intrinsic antigen-related membranous nephropathy. Nephrol Dial Transplant (2017). doi:10.1093/ndt/ gfx235

110. Tomas NM, Beck LH Jr, Meyer-Schwesinger C, Seitz-Polski B, Ma H, Zahner $\mathrm{G}$, et al. Thrombospondin type-1 domain-containing 7A in idiopathic membranous nephropathy. N Engl J Med (2014) 371(24):2277-87. doi:10.1056/ NEJMoa1409354

111. Tomas NM, Hoxha E, Reinicke AT, Fester L, Helmchen U, Gerth J, et al. Autoantibodies against thrombospondin type 1 domain-containing 7A induce membranous nephropathy. J Clin Invest (2016) 126(7):2519-32. doi:10.1172/JCI85265

112. Tomas NM, Meyer-Schwesinger C, von Spiegel H, Kotb AM, Zahner G, Hoxha E, et al. A heterologous model of thrombospondin type 1 domain-containing 7A-associated membranous nephropathy. J Am Soc Nephrol (2017) 28(11):3262-77. doi:10.1681/ASN.2017010030

113. Kronbichler A, Oh J, Meijers B, Mayer G, Shin JI. Recent progress in deciphering the etiopathogenesis of primary membranous nephropathy. Biomed Res Int (2017) 2017:1936372. doi:10.1155/2017/1936372

114. Iwakura T, Ohashi N, Kato A, Baba S, Yasuda H. Prevalence of enhanced granular expression of thrombospondin type-1 domain-containing 7A in the glomeruli of Japanese patients with idiopathic membranous nephropathy. PLoS One (2015) 10(9):e0138841. doi:10.1371/journal.pone.0138841

115. Hoxha E, Beck LH Jr, Wiech T, Tomas NM, Probst C, Mindorf S, et al. An indirect immunofluorescence method facilitates detection of thrombospondin type 1 domain-containing 7A-specific antibodies in membranous nephropathy. J Am Soc Nephrol (2017) 28(2):520-31. doi:10.1681/ASN.2016010050

116. Hoxha E, Wiech T, Stahl PR, Zahner G, Tomas NM, Meyer-Schwesinger C, et al. A mechanism for cancer-associated membranous nephropathy. $N$ Engl J Med (2016) 374(20):1995-6. doi:10.1056/NEJMc1511702

117. Iwakura T, Fujigaki Y, Katahashi N, Sato T, Ishigaki S, Tsuji N, et al. Membranous nephropathy with an enhanced granular expression of thrombospondin type-1 domain-containing 7A in a pregnant woman. Intern Med (2016) 55(18):2663-8. doi:10.2169/internalmedicine.55.6726

118. Wang J, Cui Z, Lu J, Probst C, Zhang YM, Wang X, et al. Circulating antibodies against thrombospondin type-I domain-containing $7 \mathrm{~A}$ in chinese patients with idiopathic membranous nephropathy. Clin J Am Soc Nephrol (2017) 12(10):1642-51. doi:10.2215/CJN.01460217

119. Ohlsson S, Herlitz H, Lundberg S, Selga D, Molne J, Wieslander J, et al. Circulating anti-glomerular basement membrane antibodies with predominance of subclass IgG4 and false-negative immunoassay test results in anti-glomerular basement membrane disease. Am J Kidney Dis (2014) 63(2):289-93. doi:10.1053/j.ajkd.2013.08.032

120. Cui Z, Zhao MH, Singh AK, Wang HY. Antiglomerular basement membrane disease with normal renal function. Kidney Int (2007) 72(11):1403-8. doi:10.1038/sj.ki.5002525

121. Nasr SH, Collins AB, Alexander MP, Schraith DF, Herrera Hernandez L, Fidler ME, et al. The clinicopathologic characteristics and outcome of atypical anti-glomerular basement membrane nephritis. Kidney Int (2016) 89(4):897-908. doi:10.1016/j.kint.2016.02.001

122. Qu Z, Cui Z, Liu G, Zhao MH. The distribution of IgG subclass deposition on renal tissues from patients with anti-glomerular basement membrane disease. BMC Immunol (2013) 14:19. doi:10.1186/1471-2172-14-19
123. Rosales IA, Colvin RB. Glomerular disease with idiopathic linear immunoglobulin deposition: a rose by any other name would be atypical. Kidney Int (2016) 89(4):750-2. doi:10.1016/j.kint.2016.01.018

124. Doppler K, Appeltshauser L, Villmann C, Martin C, Peles E, Kramer HH, et al. Auto-antibodies to contactin-associated protein 1 (Caspr) in two patients with painful inflammatory neuropathy. Brain (2016) 139(Pt 10):2617-30. doi:10.1093/brain/aww189

125. Hara M, Arino H, Petit-Pedrol M, Sabater L, Titulaer MJ, MartinezHernandez E, et al. DPPX antibody-associated encephalitis: main syndrome and antibody effects. Neurology (2017) 88(14):1340-8. doi:10.1212/ WNL.0000000000003796

126. Doherty L, Gold D, Solnes L, Probasco J, Venkatesan A. Anti-DPPX encephalitis: prominent nystagmus reflected by extraocular muscle FDG-PET avidity. Neurol Neuroimmunol Neuroinflamm (2017) 4(4):e361. doi:10.1212/ NXI.0000000000000361

127. Piepgras J, Holtje M, Michel K, Li Q, Otto C, Drenckhahn C, et al. Anti-DPPX encephalitis: pathogenic effects of antibodies on gut and brain neurons. Neurology (2015) 85(10):890-7. doi:10.1212/ WNL.0000000000001907

128. Boronat A, Gelfand JM, Gresa-Arribas N, Jeong HY, Walsh M, Roberts K, et al. Encephalitis and antibodies to dipeptidyl-peptidase-like protein-6, a subunit of Kv4.2 potassium channels. Ann Neurol (2013) 73(1):120-8. doi:10.1002/ana.23756

129. Tobin WO, Lennon VA, Komorowski L, Probst C, Clardy SL, Aksamit AJ, et al. DPPX potassium channel antibody: frequency, clinical accompaniments, and outcomes in 20 patients. Neurology (2014) 83(20):1797-803. doi:10.1212/WNL.0000000000000991

130. Sabater L, Gaig C, Gelpi E, Bataller L, Lewerenz J, Torres-Vega E, et al. A novel non-rapid-eye movement and rapid-eye-movement parasomnia with sleep breathing disorder associated with antibodies to IgLON5: a case series, characterisation of the antigen, and post-mortem study. Lancet Neurol (2014) 13(6):575-86. doi:10.1016/S1474-4422(14)70051-1

131. Honorat JA, Komorowski L, Josephs KA, Fechner K, St Louis EK, Hinson SR, et al. IgLON5 antibody: neurological accompaniments and outcomes in 20 patients. Neurol Neuroimmunol Neuroinflamm (2017) 4(5):e385. doi:10.1212/ NXI.0000000000000385

132. Haitao R, Yingmai Y, Yan H, Fei H, Xia L, Honglin H, et al. Chorea and parkinsonism associated with autoantibodies to IgLON5 and responsive to immunotherapy. J Neuroimmunol (2016) 300:9-10. doi:10.1016/j. jneuroim.2016.09.012

133. Bonello M, Jacob A, Ellul MA, Barker E, Parker R, Jefferson S, et al. IgLON5 disease responsive to immunotherapy. Neurolo Neuroimmunol Neuroinflamm (2017) 4(5):e383. doi:10.1212/NXI.0000000000000383

134. Sabater L, Planaguma J, Dalmau J, Graus F. Cellular investigations with human antibodies associated with the anti-IgLON5 syndrome. J Neuroinflammation (2016) 13(1):226. doi:10.1186/s12974-016-0689-1

135. Hogl B, Heidbreder A, Santamaria J, Graus F, Poewe W. IgLON5 autoimmunity and abnormal behaviours during sleep. Lancet (2015) 385(9977):1590. doi:10.1016/S0140-6736(15)60445-7

136. Schur PH. IgG subclasses. A historical perspective. Monogr Allergy (1988) 23:1-11.

137. French M. Serum IgG subclasses in normal adults. Monogr Allergy (1986) 19:100-7.

138. Aucouturier P, Danon F, Daveau M, Guillou B, Sabbah A, Besson J, et al. Measurement of serum IgG4 levels by a competitive immunoenzymatic assay with monoclonal antibodies. J Immunol Methods (1984) 74(1):151-62. doi:10.1016/0022-1759(84)90376-4

139. Briles DE, Claflin JL, Schroer K, Forman C. Mouse Igg3 antibodies are highly protective against infection with Streptococcus pneumoniae. Nature (1981) 294(5836):88-90. doi:10.1038/294088a0

140. Ey PL, Russell-Jones GJ, Jenkin CR. Isotypes of mouse IgG - I. Evidence for 'non-complement-fixing' IgG1 antibodies and characterization of their capacity to interfere with IgG2 sensitization of target red blood cells for lysis by complement. Mol Immunol (1980) 17(6):699-710. doi:10.1016/0161-5890(80)90139-X

141. Germann T, Bongartz M, Dlugonska H, Hess H, Schmitt E, Kolbe L, et al. Interleukin-12 profoundly up-regulates the synthesis of antigen-specific complement-fixing IgG2a, IgG2b and IgG3 antibody subclasses in vivo. Eur J Immunol (1995) 25(3):823-9. doi:10.1002/eji.1830250329 
142. Saadoun S, Waters P, Bell BA, Vincent A, Verkman AS, Papadopoulos MC. Intra-cerebral injection of neuromyelitis optica immunoglobulin $\mathrm{G}$ and human complement produces neuromyelitis optica lesions in mice. Brain (2010) 133(Pt 2):349-61. doi:10.1093/brain/awp309

143. Pinck JR, Milstein C. Disulphide bridges of a human immunoglobulin G protein. Nature (1967) 216(5118):941-2. doi:10.1038/216941a0

144. Frangione B, Milstein C. Disulphide bridges of immunoglobulin G-1 heavy chains. Nature (1967) 216(5118):939-41. doi:10.1038/216939b0

145. Frangione B, Milstein C, Pink JR. Structural studies of immunoglobulin G. Nature (1969) 221(5176):145-8. doi:10.1038/221145a0

146. Schroeder HW Jr, Cavacini L. Structure and function of immunoglobulins. J Allergy Clin Immunol (2010) 125(2 Suppl 2):S41-52. doi:10.1016/j. jaci.2009.09.046

147. Lighaam LC, Rispens T. The immunobiology of immunoglobulin G4. Semin Liver Dis (2016) 36(3):200-15. doi:10.1055/s-0036-1584322

148. Lu Y, Harding SE, Michaelsen TE, Longman E, Davis KG, Ortega A, et al. Solution conformation of wild-type and mutant IgG3 and IgG4 immunoglobulins using crystallohydrodynamics: possible implications for complement activation. Biophys J (2007) 93(11):3733-44. doi:10.1529/ biophysj.107.108993

149. Abe Y, Gor J, Bracewell DG, Perkins SJ, Dalby PA. Masking of the Fc region in human IgG4 by constrained X-ray scattering modelling: implications for antibody function and therapy. Biochem J (2010) 432(1):101-11. doi:10.1042/ BJ20100641

150. Tao MH, Smith RI, Morrison SL. Structural features of human immunoglobulin $\mathrm{G}$ that determine isotype-specific differences in complement activation. J Exp Med (1993) 178(2):661-7. doi:10.1084/jem.178.2.661

151. Brekke OH, Michaelsen TE, Aase A, Sandin RH, Sandlie I. Human IgG isotype-specific amino acid residues affecting complement-mediated cell lysis and phagocytosis. Eur J Immunol (1994) 24(10):2542-7. doi:10.1002/ eji.1830241042

152. Canfield SM, Morrison SL. The binding affinity of human IgG for its high affinity $\mathrm{Fc}$ receptor is determined by multiple amino acids in the $\mathrm{CH} 2$ domain and is modulated by the hinge region. J Exp Med (1991) 173(6):1483-91. doi:10.1084/jem.173.6.1483

153. Sondermann P, Huber R, Oosthuizen V, Jacob U. The 3.2-A crystal structure of the human IgG1 Fc fragment-Fc gammaRIII complex. Nature (2000) 406(6793):267-73. doi:10.1038/35018508

154. Shields RL, Namenuk AK, Hong K, Meng YG, Rae J, Briggs J, et al. High resolution mapping of the binding site on human IgG1 for Fc gamma RI, Fc gamma RII, Fc gamma RIII, and FcRn and design of IgG1 variants with improved binding to the Fc gamma R. J Biol Chem (2001) 276(9):6591-604. doi:10.1074/jbc.M009483200

155. Radaev S, Motyka S, Fridman WH, Sautes-Fridman C, Sun PD. The structure of a human type III Fcgamma receptor in complex with Fc. J Biol Chem (2001) 276(19):16469-77. doi:10.1074/jbc.M100350200

156. Schuurman J, Perdok GJ, Gorter AD, Aalberse RC. The inter-heavy chain disulfide bonds of IgG4 are in equilibrium with intra-chain disulfide bonds. Mol Immunol (2001) 38(1):1-8. doi:10.1016/S0161-5890(01)00050-5

157. Bloom JW, Madanat MS, Marriott D, Wong T, Chan SY. Intrachain disulfide bond in the core hinge region of human IgG4. Protein Sci (1997) 6(2):407-15. doi:10.1002/pro.5560060217

158. Angal S, King DJ, Bodmer MW, Turner A, Lawson AD, Roberts G, et al. A single amino acid substitution abolishes the heterogeneity of chimeric mouse/human (IgG4) antibody. Mol Immunol (1993) 30(1):105-8. doi:10.1016/0161-5890(93)90432-B

159. Davies AM, Rispens T, den Bleker TH, McDonnell JM, Gould HJ, Aalberse $\mathrm{RC}$, et al. Crystal structure of the human IgG4 C(H)3 dimer reveals the role of Arg409 in the mechanism of Fab-arm exchange. Mol Immunol (2013) 54(1):1-7. doi:10.1016/j.molimm.2012.10.029

160. Labrijn AF, Rispens T, Meesters J, Rose RJ, den Bleker TH, Loverix S, et al. Species-specific determinants in the IgG $\mathrm{CH} 3$ domain enable Fab-arm exchange by affecting the noncovalent $\mathrm{CH} 3-\mathrm{CH} 3$ interaction strength. J Immunol (2011) 187(6):3238-46. doi:10.4049/jimmunol.1003336

161. King DJ, Adair JR, Angal S, Low DC, Proudfoot KA, Lloyd JC, et al. Expression, purification and characterization of a mouse-human chimeric antibody and chimeric Fab' fragment. Biochem J (1992) 281(Pt 2):317-23. doi:10.1042/bj2810317
162. Margni RA, Binaghi RA. Nonprecipitating asymmetric antibodies. Annu Rev Immunol (1988) 6:535-54. doi:10.1146/annurev.iy.06.040188.002535

163. van der Zee JS, van Swieten P, Aalberse RC. Serologic aspects of IgG4 antibodies. II. IgG4 antibodies form small, nonprecipitating immune complexes due to functional monovalency. J Immunol (1986) 137(11):3566-71.

164. Petersen JG, Dorrington KJ. An in vitro system for studying the kinetics of interchain disulfide bond formation in immunoglobulin G. J Biol Chem (1974) 249(17):5633-41.

165. Colcher D, Milenic D, Roselli M, Raubitschek A, Yarranton G, King D, et al. Characterization and biodistribution of recombinant and recombinant/ chimeric constructs of monoclonal antibody B72.3. Cancer Res (1989) 49(7):1738-45.

166. van der Neut Kolfschoten M, Schuurman J, Losen M, Bleeker WK, MartinezMartinez P, Vermeulen E, et al. Anti-inflammatory activity of human IgG4 antibodies by dynamic Fab arm exchange. Science (2007) 317(5844):1554-7. doi:10.1126/science. 1144603

167. Rispens T, Davies AM, Ooijevaar-de Heer P, Absalah S, Bende O, Sutton BJ, et al. Dynamics of inter-heavy chain interactions in human immunoglobulin G (IgG) subclasses studied by kinetic Fab arm exchange. J Biol Chem (2014) 289(9):6098-109. doi:10.1074/jbc.M113.541813

168. Vidarsson G, Dekkers G, Rispens T. IgG subclasses and allotypes: from structure to effector functions. Front Immunol (2014) 5:520. doi:10.3389/ fimmu.2014.00520

169. Nirula A, Glaser SM, Kalled SL, Taylor FR. What is IgG4? A review of the biology of a unique immunoglobulin subtype. Curr Opin Rheumatol (2011) 23(1):119-24. doi:10.1097/BOR.0b013e3283412fd4

170. Aalberse RC, Stapel SO, Schuurman J, Rispens T. Immunoglobulin G4: an odd antibody. Clin Exp Allergy (2009) 39(4):469-77. doi:10.1111/j.1365-2222.2009.03207.x

171. Hansen K, Ruttekolk IR, Glauner H, Becker F, Brock R, Hannus S. The in vitro biological activity of the HLA-DR-binding clinical IgG4 antibody 1D09C3 is a consequence of the disruption of cell aggregates and can be abrogated by Fab arm exchange. Mol Immunol (2009) 46(16):3269-77. doi:10.1016/j. molimm.2009.07.031

172. Labrijn AF, Buijsse AO, van den Bremer ET, Verwilligen AY, Bleeker WK, Thorpe SJ, et al. Therapeutic IgG4 antibodies engage in Fab-arm exchange with endogenous human IgG4 in vivo. Nat Biotechnol (2009) 27(8):767-71. doi:10.1038/nbt.1553

173. Young E, Lock E, Ward DG, Cook A, Harding S, Wallis GL. Estimation of polyclonal IgG4 hybrids in normal human serum. Immunology (2014) 142(3):406-13. doi:10.1111/imm.12265

174. Rispens T, Ooijevaar-de Heer P, Bende O, Aalberse RC. Mechanism of immunoglobulin G4 Fab-arm exchange. J Am Chem Soc (2011) 133(26):10302-11. doi:10.1021/ja203638y

175. Stubenrauch K, Wessels U, Regula JT, Kettenberger H, Schleypen J, Kohnert $\mathrm{U}$. Impact of molecular processing in the hinge region of therapeutic IgG4 antibodies on disposition profiles in cynomolgus monkeys. Drug Metab Dispos (2010) 38(1):84-91. doi:10.1124/dmd.109.029751

176. Rispens T, den Bleker TH, Aalberse RC. Hybrid IgG4/IgG4 Fc antibodies form upon 'Fab-arm' exchange as demonstrated by SDS-PAGE or size-exclusion chromatography. Mol Immunol (2010) 47(7-8):1592-4. doi:10.1016/j. molimm.2010.02.021

177. Jones DP, Liang Y. Measuring the poise of thiol/disulfide couples in vivo. Free Radic Biol Med (2009) 47(10):1329-38. doi:10.1016/j. freeradbiomed.2009.08.021

178. Shapiro RI, Plavina T, Schlain BR, Pepinsky RB, Garber EA, Jarpe M, et al. Development and validation of immunoassays to quantify the half-antibody exchange of an IgG4 antibody, natalizumab (Tysabri(R)) with endogenous IgG4. J Pharm Biomed Anal (2011) 55(1):168-75. doi:10.1016/j. jpba.2011.01.006

179. Bonilla FA. Pharmacokinetics of immunoglobulin administered via intravenous or subcutaneous routes. Immunol Allergy Clin North Am (2008) 28(4):803-19, ix. doi:10.1016/j.iac.2008.06.006

180. Koneczny I. Potential Mechanisms in MuSK Myasthenia Gravis [Dissertation]. Oxford: Oxford University (2014)

181. Rispens T, Ooievaar-De Heer P, Vermeulen E, Schuurman J, van der Neut Kolfschoten M, Aalberse RC. Human IgG4 binds to IgG4 and 
conformationally altered IgG1 via Fc-Fc interactions. J Immunol (2009) 182(7):4275-81. doi:10.4049/jimmunol.0804338

182. Zack DJ, Stempniak M, Wong AL, Weisbart RH. Localization of an Fc-binding reactivity to the constant region of human IgG4. Implications for the pathogenesis of rheumatoid arthritis. J Immunol (1995) 155(10):5057-63.

183. Kawa S, Kitahara K, Hamano H, Ozaki Y, Arakura N, Yoshizawa K, et al. A novel immunoglobulin-immunoglobulin interaction in autoimmunity. PLoS One (2008) 3(2):e1637. doi:10.1371/journal.pone.0001637

184. Cohen PL, Cheek RL, Hadler JA, Yount WJ, Eisenberg RA. The subclass distribution of human IgG rheumatoid factor. JImmunol (1987) 139(5):1466-71.

185. Detlefsen S, Brasen JH, Zamboni G, Capelli P, Kloppel G. Deposition of complement C3c, immunoglobulin (Ig)G4 and IgG at the basement membrane of pancreatic ducts and acini in autoimmune pancreatitis. Histopathology (2010) 57(6):825-35. doi:10.1111/j.1365-2559.2010.03717.x

186. Ma H, Sandor DG, Beck LH Jr. The role of complement in membranous nephropathy. Semin Nephrol (2013) 33(6):531-42. doi:10.1016/j. semnephrol.2013.08.004

187. Diebolder CA, Beurskens FJ, de Jong RN, Koning RI, Strumane K, Lindorfer MA, et al. Complement is activated by IgG hexamers assembled at the cell surface. Science (2014) 343(6176):1260-3. doi:10.1126/science.1248943

188. Lichtenstein LM, Holtzman NA, Burnett LS. A quantitative in vitro study of the chromatographic distribution and immunoglobulin characteristics of human blocking antibody. J Immunol (1968) 101(2):317-24.

189. Punnonen J, Aversa G, Cocks BG, McKenzie AN, Menon S, Zurawski G, et al. Interleukin 13 induces interleukin 4-independent IgG4 and IgE synthesis and CD23 expression by human B cells. Proc Natl Acad Sci U S A (1993) 90(8):3730-4. doi:10.1073/pnas.90.8.3730

190. Meiler F, Zumkehr J, Klunker S, Ruckert B, Akdis CA, Akdis M. In vivo switch to IL-10-secreting T regulatory cells in high dose allergen exposure. J Exp Med (2008) 205(12):2887-98. doi:10.1084/jem.20080193

191. Meiler F, Klunker S, Zimmermann M, Akdis CA, Akdis M. Distinct regulation of IgE, IgG4 and IgA by T regulatory cells and toll-like receptors. Allergy (2008) 63(11):1455-63. doi:10.1111/j.1398-9995.2008.01774.x

192. Jeannin P, Lecoanet S, Delneste Y, Gauchat JF, Bonnefoy JY. IgE versus IgG4 production can be differentially regulated by IL-10. J Immunol (1998) 160(7):3555-61.

193. Satoguina JS, Weyand E, Larbi J, Hoerauf A. T regulatory-1 cells induce IgG4 production by B cells: role of IL-10. J Immunol (2005) 174(8):4718-26. doi:10.4049/jimmunol.174.8.4718

194. van de Veen W, Stanic B, Yaman G, Wawrzyniak M, Sollner S, Akdis DG, et al. IgG4 production is confined to human IL-10-producing regulatory B cells that suppress antigen-specific immune responses. J Allergy Clin Immunol (2013) 131(4):1204-12. doi:10.1016/j.jaci.2013.01.014

195. Aalberse RC, van der Gaag R, van Leeuwen J. Serologic aspects of IgG4 antibodies. I. Prolonged immunization results in an IgG4-restricted response. J Immunol (1983) 130(2):722-6.

196. Nakagawa T, Miyamoto T. The role of IgG4 as blocking antibodies in asthmatics and in bee keepers. Int Arch Allergy Appl Immunol (1985) 77(1-2):204-5. doi: $10.1159 / 000233787$

197. Platts-Mills T, Vaughan J, Squillace S, Woodfolk J, Sporik R. Sensitisation, asthma, and a modified $\mathrm{Th} 2$ response in children exposed to cat allergen: a population-based cross-sectional study. Lancet (2001) 357(9258):752-6. doi:10.1016/S0140-6736(00)04168-4

198. James LK, Bowen H, Calvert RA, Dodev TS, Shamji MH, Beavil AJ, et al. Allergen specificity of $\operatorname{IgG}(4)$-expressing B cells in patients with grass pollen allergy undergoing immunotherapy. J Allergy Clin Immunol (2012) 130(3):663-70.e3. doi:10.1016/j.jaci.2012.04.006

199. Van der Zee S, Aalberse RC. IgG4 and hyposensitization. N Engl Reg Allergy Proc (1987) 8(6):389-91. doi:10.2500/108854187778999667

200. van der Zee JS, van Swieten P, Aalberse RC. Inhibition of complement activation by IgG4 antibodies. Clin Exp Immunol (1986) 64(2):415-22.

201. Margni RA, Perdigon G, Abatangelo C, Gentile T, Binaghi RA. Immunobiological behaviour of rabbit precipitating and non-precipitating (co-precipitating) antibodies. Immunology (1980) 41(3):681-6.

202. van Toorenenbergen AW, Aalberse RC. IgG4 and release of histamine from human peripheral blood leukocytes. Int Arch Allergy Appl Immunol (1982) 67(2):117-22. doi:10.1159/000233000
203. Aalberse RC, Dieges PH, Knul-Bretlova V, Vooren P, Aalbers M, van Leeuwen J. IgG4 as a blocking antibody. Clin Rev Allergy (1983) 1(2):289-302.

204. Santos AF, James LK, Bahnson HT, Shamji MH, Couto-Francisco NC, Islam S, et al. IgG4 inhibits peanut-induced basophil and mast cell activation in peanut-tolerant children sensitized to peanut major allergens. J Allergy Clin Immunol (2015) 135(5):1249-56. doi:10.1016/j.jaci.2015.01.012

205. Kemeny DM, MacKenzie-Mills M, Harries MG, Youlten LJ, Lessof MH. Antibodies to purified bee venom proteins and peptides. II. A detailed study of changes in IgE and IgG antibodies to individual bee venom antigens. J Allergy Clin Immunol (1983) 72(4):376-85. doi:10.1016/0091-6749(83)90503-1

206. Kemeny DM, McKenzie-Mills M, Harries MG, Youlten LJ, Lessof MH. Changes in the levels of anti-phospholipase A2 and hyaluronidase antibodies during bee venom immunotherapy. Monogr Allergy (1983) 18:150-2.

207. Schumacher MJ, Egen NB, Tanner D. Neutralization of bee venom lethality by immune serum antibodies. Am J Trop Med Hyg (1996) 55(2):197-201. doi:10.4269/ajtmh.1996.55.197

208. Drachman DB, AngusCW,AdamsRN, MichelsonJD, Hoffman GJ. Myasthenic antibodies cross-link acetylcholine receptors to accelerate degradation. $N$ Engl J Med (1978) 298(20):1116-22. doi:10.1056/NEJM197805182982004

209. Heinemann S, Bevan S, Kullberg R, Lindstrom J, Rice J. Modulation of acetylcholine receptor by antibody against the receptor. Proc Natl Acad Sci U S A (1977) 74(7):3090-4. doi:10.1073/pnas.74.7.3090

210. Hughes EG, Peng X, Gleichman AJ, Lai M, Zhou L, Tsou R, et al. Cellular and synaptic mechanisms of anti-NMDA receptor encephalitis. J Neurosci (2010) 30(17):5866-75. doi:10.1523/JNEUROSCI.0167-10.2010

211. Moscato EH, Peng X, Jain A, Parsons TD, Dalmau J, Balice-Gordon RJ. Acute mechanisms underlying antibody effects in anti-N-methyl-D-aspartate receptor encephalitis. Ann Neurol (2014) 76(1):108-19. doi:10.1002/ ana. 24195

212. Lai M, Hughes EG, Peng X, Zhou L, Gleichman AJ, Shu H, et al. AMPA receptor antibodies in limbic encephalitis alter synaptic receptor location. Ann Neurol (2009) 65(4):424-34. doi:10.1002/ana.21589

213. Peng X, Hughes EG, Moscato EH, Parsons TD, Dalmau J, Balice-Gordon RJ. Cellular plasticity induced by anti-alpha-amino-3-hydroxy-5-methyl-4-isoxazolepropionic acid (AMPA) receptor encephalitis antibodies. Ann Neurol (2015) 77(3):381-98. doi:10.1002/ana.24293

214. Collins AM, Davies JM. Enhanced cell-binding by allergen multimers: how complex is it? Immunol Cell Biol (2013) 91(2):115-7. doi:10.1038/icb.2013.5

215. Naparstek Y, Plotz PH. The role of autoantibodies in autoimmune disease. Anпu Rev Immunol (1993) 11:79-104. doi:10.1146/annurev. iy.11.040193.000455

216. Skeie GO, Aarli JA, Gilhus NE. Titin and ryanodine receptor antibodies in myasthenia gravis. Acta Neurol Scand Suppl (2006) 183:19-23. doi:10.1111/j.1600-0404.2006.00608.x

217. Witebsky E, Rose NR, Terplan K, Paine JR, Egan RW. Chronic thyroiditis and autoimmunization. J Am Med Assoc (1957) 164(13):1439-47. doi:10.1001/ jama.1957.02980130015004

218. Rose NR, Bona C. Defining criteria for autoimmune diseases (Witebsky's postulates revisited). Immunol Today (1993) 14(9):426-30. doi:10.1016/0167-5699(93)90244-F

219. Ishii K, Harada R, Matsuo I, Shirakata Y, Hashimoto K, Amagai M. In vitro keratinocyte dissociation assay for evaluation of the pathogenicity of anti-desmoglein $3 \mathrm{IgG}$ autoantibodies in pemphigus vulgaris. J Invest Dermatol (2005) 124(5):939-46. doi:10.1111/j.0022-202X.2005.23714.x

220. Funakoshi T, Lunardon L, Ellebrecht CT, Nagler AR, O'Leary CE, Payne AS. Enrichment of total serum IgG4 in patients with pemphigus. $\mathrm{Br}$ J Dermatol (2012) 167(6):1245-53. doi:10.1111/j.1365-2133.2012.11144.x

221. Lo AS, Mao X, Mukherjee EM, Ellebrecht CT, Yu X, Posner MR, et al. Pathogenicity and epitope characteristics do not differ in IgG subclass-switched anti-desmoglein 3 IgG1 and IgG4 autoantibodies in pemphigus vulgaris. PLoS One (2016) 11(6):e0156800. doi:10.1371/journal. pone. 0156800

222. Waschke J, Spindler V, Bruggeman P, Zillikens D, Schmidt G, Drenckhahn D. Inhibition of Rho A activity causes pemphigus skin blistering. J Cell Biol (2006) 175(5):721-7. doi:10.1083/jcb.200605125

223. Li N, Zhao M, Wang J, Liu Z, Diaz LA. Involvement of the apoptotic mechanism in pemphigus foliaceus autoimmune injury of the skin. J Immunol (2009) 182(1):711-7. doi:10.4049/jimmunol.182.1.711 
224. Cipolla GA, Park JK, Lavker RM, Petzl-Erler ML. Crosstalk between signaling pathways in pemphigus: a role for endoplasmic reticulum stress in p38 mitogen-activated protein kinase activation? Front Immunol (2017) 8:1022. doi:10.3389/fimmu.2017.01022

225. Egu DT, Walter E, Spindler V, Waschke J. Inhibition of p38MAPK signaling prevents epidermal blistering and alterations of desmosome structure induced by pemphigus autoantibodies in human epidermis. Br J Dermatol (2017) 177(6):1612-8. doi:10.1111/bjd.15721

226. Mavropoulos A, Orfanidou T, Liaskos C, Smyk DS, Spyrou V, Sakkas LI, et al. p38 MAPK signaling in pemphigus: implications for skin autoimmunity. Autoimmune Dis (2013) 2013:728529. doi:10.1155/2013/728529

227. Spindler V, Vielmuth F, Schmidt E, Rubenstein DS, Waschke J. Protective endogenous cyclic adenosine 5'-monophosphate signaling triggered by pemphigus autoantibodies. J Immunol (2010) 185(11):6831-8. doi:10.4049/ jimmunol.1002675

228. Walter E, Vielmuth F, Rotkopf L, Sardy M, Horvath ON, Goebeler M, et al. Different signaling patterns contribute to loss of keratinocyte cohesion dependent on autoantibody profile in pemphigus. Sci Rep (2017) 7(1):3579. doi:10.1038/s41598-017-03697-7

229. Spindler V, Eming R, Schmidt E, Amagai M, Grando S, Jonkman MF, et al. Mechanisms causing loss of keratinocyte cohesion in pemphigus. J Invest Dermatol (2017) 138(1):32-7. doi:10.1016/j.jid.2017.06.022

230. Huda S, Cao M, De Rosa A, Woodhall M, Cossins J, Maestri M, et al. Inhibition of the tyrosine phosphatase Shp2 alleviates the pathogenic effects of MuSK antibodies in vitro. Neuromuscul Dis (2007) 27:S36. doi:10.1016/ S0960-8966(17)30325-5

231. Niks EH, Kuks JB, Wokke JH, Veldman H, Bakker E, Verschuuren JJ, et al. Pre- and postsynaptic neuromuscular junction abnormalities in musk myasthenia. Muscle Nerve (2010) 42(2):283-8. doi:10.1002/mus.21642

232. Yumoto N, Kim N, Burden SJ. Lrp4 is a retrograde signal for presynaptic differentiation at neuromuscular synapses. Nature (2012) 489(7416):438-42. doi:10.1038/nature11348

233. Wu H, Lu Y, Shen C, Patel N, Gan L, Xiong WC, et al. Distinct roles of muscle and motoneuron LRP4 in neuromuscular junction formation. Neuron (2012) 75(1):94-107. doi:10.1016/j.neuron.2012.04.033

234. Thomas MR, de Groot R, Scully MA, Crawley JT. Pathogenicity of antiADAMTS13 autoantibodies in acquired thrombotic thrombocytopenic purpura. EBioMedicine (2015) 2(8):942-52. doi:10.1016/j.ebiom.2015.06.007

235. Kremer Hovinga JA, Coppo P, Lammle B, Moake JL, Miyata T, Vanhoorelbeke K. Thrombotic thrombocytopenic purpura. Nat Rev Dis Primers (2017) 3:17020. doi:10.1038/nrdp.2017.20

236. Faivre-Sarrailh C, Devaux JJ. Neuro-glial interactions at the nodes of Ranvier: implication in health and diseases. Front Cell Neurosci (2013) 7:196. doi:10.3389/fncel.2013.00196

237. Peles E, Nativ M, Lustig M, Grumet M, Schilling J, Martinez R, et al. Identification of a novel contactin-associated transmembrane receptor with multiple domains implicated in protein-protein interactions. EMBO J (1997) 16(5):978-88. doi:10.1093/emboj/16.5.978

238. Rios JC, Melendez-Vasquez CV, Einheber S, Lustig M, Grumet M, Hemperly $\mathrm{J}$, et al. Contactin-associated protein (Caspr) and contactin form a complex that is targeted to the paranodal junctions during myelination. J Neurosci (2000) 20(22):8354-64.

239. Charles P, Tait S, Faivre-Sarrailh C, Barbin G, Gunn-Moore F, DenisenkoNehrbass N, et al. Neurofascin is a glial receptor for the paranodin/ Caspr-contactin axonal complex at the axoglial junction. Curr Biol (2002) 12(3):217-20. doi:10.1016/S0960-9822(01)00680-7

240. Malhotra R, Wormald MR, Rudd PM, Fischer PB, Dwek RA, Sim RB. Glycosylation changes of IgG associated with rheumatoid arthritis can activate complement via the mannose-binding protein. Nat Med (1995) 1(3):237-43. doi:10.1038/nm0395-237

241. Roos A, Bouwman LH, van Gijlswijk-Janssen DJ, Faber-Krol MC, Stahl GL, Daha MR. Human IgA activates the complement system via the mannan-binding lectin pathway. J Immunol (2001) 167(5):2861-8. doi:10.4049/ jimmunol.167.5.2861

242. Bally S, Debiec H, Ponard D, Dijoud F, Rendu J, Faure J, et al. Phospholipase A2 receptor-related membranous nephropathy and mannan-binding lectin deficiency. J Am Soc Nephrol (2016) 27(12):3539-44. doi:10.1681/ ASN.2015101155
243. Hofstra JM, Debiec H, Short CD, Pelle T, Kleta R, Mathieson PW, et al. Antiphospholipase A2 receptor antibody titer and subclass in idiopathic membranous nephropathy. JAm Soc Nephrol (2012) 23(10):1735-43. doi:10.1681/ASN.2012030242

244. Debiec H, Hanoy M, Francois A, Guerrot D, Ferlicot S, Johanet C, et al. Recurrent membranous nephropathy in an allograft caused by IgG3kappa targeting the PLA2 receptor. JAm Soc Nephrol (2012) 23(12):1949-54. doi:10.1681/ASN.2012060577

245. Skoberne A, Behnert A, Teng B, Fritzler MJ, Schiffer L, Pajek J, et al. Serum with phospholipase A2 receptor autoantibodies interferes with podocyte adhesion to collagen. Eur J Clin Invest (2014) 44(8):753-65. doi:10.1111/ eci. 12292

246. Jurgensen HJ, Johansson K, Madsen DH, Porse A, Melander MC, Sorensen $\mathrm{KR}$, et al. Complex determinants in specific members of the mannose receptor family govern collagen endocytosis. J Biol Chem (2014) 289(11):7935-47. doi:10.1074/jbc.M113.512780

247. Foster MH. Optimizing the translational value of animal models of glomerulonephritis: insights from recent murine prototypes. Am J Physiol Ren Physiol (2016) 311(3):F487-95. doi:10.1152/ajprenal.00275.2016

248. Lai M, Huijbers MG, Lancaster E, Graus F, Bataller L, Balice-Gordon R, et al. Investigation of LGI1 as the antigen in limbic encephalitis previously attributed to potassium channels: a case series. Lancet Neurol (2010) 9(8):776-85. doi:10.1016/S1474-4422(10)70137-X

249. Irani SR, Michell AW, Lang B, Pettingill P, Waters P, Johnson MR, et al. Faciobrachial dystonic seizures precede Lgil antibody limbic encephalitis. Ann Neurol (2011) 69(5):892-900. doi:10.1002/ana.22307

250. van Sonderen A, Petit-Pedrol M, Dalmau J, Titulaer MJ. The value of LGI1, Caspr2 and voltage-gated potassium channel antibodies in encephalitis. Nat Rev Neurol (2017) 13(5):290-301. doi:10.1038/nrneurol.2017.43

251. Vincent A, Irani SR. Caspr2 antibodies in patients with thymomas. $J$ Thorac Oncol (2010) 5(10 Suppl 4):S277-80. doi:10.1097/JTO.0b013e3181f23f04

252. Vale TC, Pedroso JL, Dutra LA, Azevedo L, Filho LH, Prado LB, et al. Morvan syndrome as a paraneoplastic disorder of thymoma with antiCASPR2 antibodies. Lancet (2017) 389(10076):1367-8. doi:10.1016/ S0140-6736(16)31459-3

253. Carvajal-Gonzalez A, Leite MI, Waters P, Woodhall M, Coutinho E, Balint $B$, et al. Glycine receptor antibodies in PERM and related syndromes: characteristics, clinical features and outcomes. Brain (2014) 137(Pt 8):2178-92. doi:10.1093/brain/awu142

254. Ahmad M, Mahajan VS, Mattoo H, Stone JH, Pillai S. Individuals with IgG4related disease do not have an increased frequency of the K409 variant of IgG4 that compromises Fab-arm exchange. J Rheumatol (2014) 41(1):185-7. doi:10.3899/jrheum.131017

255. Hao M, Li W, Yi L, Yu S, Fan G, Lu T, et al. Hybrid kappallambda antibody is a new serological marker to diagnose autoimmune pancreatitis and differentiate it from pancreatic cancer. Sci Rep (2016) 6:27415. doi:10.1038/ srep27415

256. Yi L, Hao M, Lu T, Lin G, Chen L, Gao M, et al. Increased kappa/lambda hybrid antibody in serum is a novel biomarker related to disease activity and inflammation in rheumatoid arthritis. Mediators Inflamm (2016) 2016:2953072. doi: $10.1155 / 2016 / 2953072$

257. Howard FM Jr, Lennon VA, Finley J, Matsumoto J, Elveback LR. Clinical correlations of antibodies that bind, block, or modulate human acetylcholine receptors in myasthenia gravis. Ann N Y Acad Sci (1987) 505:526-38. doi:10 .1111/j.1749-6632.1987.tb51321.x

258. Shibuya N, Mori K, Nakazawa Y. Serum factor blocks neuromuscular transmission in myasthenia gravis: electrophysiologic study with intracellular microelectrodes. Neurology (1978) 28(8):804-11. doi:10.1212/WNL.28.8.804

259. Vincent A, Li Z, Hart A, Barrett-Jolley R, Yamamoto T, Burges J, et al. Seronegative myasthenia gravis. Evidence for plasma factor(s) interfering with acetylcholine receptor function. Ann N Y Acad Sci (1993) 681:529-38. doi:10.1111/j.1749-6632.1993.tb22936.x

260. Rapoport B, Chazenbalk GD, Jaume JC, McLachlan SM. The thyrotropin (TSH) receptor: interaction with TSH and autoantibodies. Endocr Rev (1998) 19(6):673-716. doi:10.1210/edrv.19.6.0352

261. Drexhage HA, Bottazzo GF, Bitensky L, Chayen J, Doniach D. Thyroid growth-blocking antibodies in primary myxoedema. Nature (1981) 289(5798):594-6. doi:10.1038/289594a0 
262. Engel AG, Lambert EH, Howard FM. Immune complexes (IgG and C3) at the motor end-plate in myasthenia gravis: ultrastructural and light microscopic localization and electrophysiologic correlations. Mayo Clin Proc (1977) 52(5):267-80

263. Sahashi K, Engel AG, Lambert EH, Howard FM Jr. Ultrastructural localization of the terminal and lytic ninth complement component (C9) at the motor end-plate in myasthenia gravis. J Neuropathol Exp Neurol (1980) 39(2):160-72. doi:10.1097/00005072-198003000-00005

264. Lennon VA, Lambert EH. Monoclonal autoantibodies to acetylcholine receptors: evidence for a dominant idiotype and requirement of complement for pathogenicity. Ann N Y Acad Sci (1981) 377:77-96. doi:10.111 1/j.1749-6632.1981.tb33725.x

265. Misu T, Hoftberger R, Fujihara K, Wimmer I, Takai Y, Nishiyama S, et al. Presence of six different lesion types suggests diverse mechanisms of tissue injury in neuromyelitis optica. Acta Neuropathol (2013) 125(6):815-27. doi:10.1007/s00401-013-1116-7

266. Huijbers MG, Querol LA, Niks EH, Plomp JJ, van der Maarel SM, Graus F, et al. The expanding field of IgG4-mediated neurological autoimmune disorders. Eur J Neurol (2015) 22(8):1151-61. doi:10.1111/ene.12758

267. Binks SNM, Klein CJ, Waters P, Pittock SJ, Irani SR. LGI1, CASPR2 and related antibodies: a molecular evolution of the phenotypes. JNeurol Neurosurg Psychiatry (2017). doi:10.1136/jnnp-2017-315720

268. Phillips WD, Vincent A. Pathogenesis of myasthenia gravis: update on disease types, models, and mechanisms. F1000Res (2016) 5(F1000 Faculty Rev):1513. doi:10.12688/f1000research.8206.1

269. Dalmau J, Geis C, Graus F. Autoantibodies to synaptic receptors and neuronal cell surface proteins in autoimmune diseases of the central nervous system. Physiol Rev (2017) 97(2):839-87. doi:10.1152/physrev.00010.2016

270. Alenzi FQ, Salem ML, Alenazi FA, Wyse RK. Cellular and molecular aspects of Goodpasture syndrome. Iran J Kidney Dis (2012) 6(1):1-8.

271. Aoki V, Rivitti EA, Diaz LA; Cooperative Group on Fogo Selvagem Research. Update on fogo selvagem, an endemic form of pemphigus foliaceus. J Dermatol (2015) 42(1):18-26. doi:10.1111/1346-8138.12675

272. Anandan V, Jameela WA, Sowmiya R, Kumar MMS, Lavanya P. Rituximab: a magic bullet for pemphigus. J Clin Diagn Res (2017) 11(4):WC01-6. doi:10.7860/JCDR/2017/21868.9717

273. Schmidt E. Rituximab as first-line treatment of pemphigus. Lancet (2017) 389(10083):1956-8. doi:10.1016/S0140-6736(17)30787-0

274. Kanwar AJ, Vinay K, Sawatkar GU, Dogra S, Minz RW, Shear NH, et al. Clinical and immunological outcomes of high- and low-dose rituximab treatments in patients with pemphigus: a randomized, comparative, observer-blinded study. Br J Dermatol (2014) 170(6):1341-9. doi:10.1111/bjd.12972

275. Appeltshauser L, Weishaupt A, Sommer C, Doppler K. Complement deposition induced by binding of anti-contactin-1 auto-antibodies is modified by immunoglobulins. Exp Neurol (2017) 287(Pt 1):84-90. doi:10.1016/j. expneurol.2016.10.006

276. Gelpi E, Hoftberger R, Graus F, Ling H, Holton JL, Dawson T, et al. Neuropathological criteria of anti-IgLON5-related tauopathy. Acta Neuropathol (2016) 132(4):531-43. doi:10.1007/s00401-016-1591-8

277. Cagnin A, Mariotto S, Fiorini M, Gaule M, Bonetto N, Tagliapietra M, et al. Microglial and neuronal TDP-43 pathology in anti-IgLON5-related tauopathy. J Alzheimers Dis (2017) 59(1):13-20. doi:10.3233/JAD-170189

278. Mori S, Motohashi N, Takashima R, Kishi M, Nishimune H, Shigemoto K. Immunization of mice with LRP4 induces myasthenia similar to MuSKassociated myasthenia gravis. Exp Neurol (2017) 297:158-67. doi:10.1016/j. expneurol.2017.08.006

279. Tezuka T, Inoue A, Hoshi T, Weatherbee SD, Burgess RW, Ueta R, et al. The MuSK activator agrin has a separate role essential for postnatal maintenance of neuromuscular synapses. Proc Natl Acad Sci U S A (2014) 111(46):1655661. doi:10.1073/pnas.1408409111

280. Maselli RA, Arredondo J, Cagney O, Ng JJ, Anderson JA, Williams C, et al. Mutations in MUSK causing congenital myasthenic syndrome impair MuSKDok-7 interaction. Hum Mol Genet (2010) 19(12):2370-9. doi:10.1093/hmg/ ddq110

281. Zhu D, Yang Z, Luo Z, Luo S, Xiong WC, Mei L. Muscle-specific receptor tyrosine kinase endocytosis in acetylcholine receptor clustering in response to agrin. JNeurosci (2008) 28(7):1688-96. doi:10.1523/ JNEUROSCI.4130-07.2008
282. Luiskandl S, Woller B, Schlauf M, Schmid JA, Herbst R. Endosomal trafficking of the receptor tyrosine kinase MuSK proceeds via clathrin-dependent pathways, Arf6 and actin. FEBS J (2013) 280(14):3281-97. doi:10.1111/ febs. 12309

283. Woller B, Luiskandl S, Popovic M, Prieler BE, Ikonge G, Mutzl M, et al. Rinlike, a novel regulator of endocytosis, acts as guanine nucleotide exchange factor for Rab5a and Rab22. Biochim Biophys Acta (2011) 1813(6):1198-210. doi:10.1016/j.bbamcr.2011.03.005

284. Scheiflinger F, Knobl P, Trattner B, Plaimauer B, Mohr G, Dockal M, et al. Nonneutralizing IgM and IgG antibodies to von Willebrand factor-cleaving protease (ADAMTS-13) in a patient with thrombotic thrombocytopenic purpura. Blood (2003) 102(9):3241-3. doi:10.1182/ blood-2003-05-1616

285. Huang CC, Lehman A, Albawardi A, Satoskar A, Brodsky S, Nadasdy G, et al. IgG subclass staining in renal biopsies with membranous glomerulonephritis indicates subclass switch during disease progression. Mod Pathol (2013) 26(6):799-805. doi:10.1038/modpathol.2012.237

286. Raibagkar P, Ferry JA, Stone JH. Is MuSK myasthenia gravis linked to IgG4-related disease? J Neuroimmunol (2017) 305:82-3. doi:10.1016/j. jneuroim.2017.02.004

287. Saeki T, Ito T, Youkou A, Ishiguro H, Sato N, Yamazaki H, et al. Thrombotic thrombocytopenic purpura in IgG4-related disease with severe deficiency of ADAMTS-13 activity and IgG4 autoantibody against ADAMTS-13. Arthritis Care Res (Hoboken) (2011) 63(8):1209-12. doi:10.1002/acr.20484

288. Stone JH, Khosroshahi A, Deshpande V, Chan JK, Heathcote JG, Aalberse $\mathrm{R}$, et al. Recommendations for the nomenclature of IgG4-related disease and its individual organ system manifestations. Arthritis Rheum (2012) 64(10):3061-7. doi:10.1002/art.34593

289. Bozzalla Cassione E, Stone JH. IgG4-related disease. Curr Opin Rheumatol (2017) 29(3):223-7. doi:10.1097/BOR.0000000000000383

290. Trampert DC, Hubers LM, van de Graaf SFJ, Beuers U. On the role of IgG4 in inflammatory conditions: lessons for IgG4-related disease. Biochim Biophys Acta (2017). doi:10.1016/j.bbadis.2017.07.038

291. Umehara H, Okazaki K, Kawano M, Mimori T, Chiba T. How to diagnose IgG4-related disease. Ann Rheum Dis (2017) 76(11):e46. doi:10.1136/ annrheumdis-2017-211330

292. Hertl M, Jedlickova H, Karpati S, Marinovic B, Uzun S, Yayli S, et al. Pemphigus. S2 Guideline for diagnosis and treatment - guided by the European Dermatology Forum (EDF) in cooperation with the European Academy of Dermatology and Venereology (EADV). J Eur Acad Dermatol Venereol (2015) 29(3):405-14. doi:10.1111/jdv.12772

293. Mattoo H, Mahajan VS, Della-Torre E, Sekigami Y, Carruthers M, Wallace ZS, et al. De novo oligoclonal expansions of circulating plasmablasts in active and relapsing IgG4-related disease. J Allergy Clin Immunol (2014) 134(3):679-87. doi:10.1016/j.jaci.2014.03.034

294. Della Torre E, Bozzolo EP, Passerini G, Doglioni C, Sabbadini MG. IgG4-related pachymeningitis: evidence of intrathecal IgG4 on cerebrospinal fluid analysis. Ann Intern Med (2012) 156(5):401-3. doi:10.7326/0003-4819-156-5-201203060-00025

295. Maillette de Buy Wenniger LJ, Doorenspleet ME, Klarenbeek PL, Verheij J, Baas F, Elferink RP, et al. Immunoglobulin G4+ clones identified by next-generation sequencing dominate the $\mathrm{B}$ cell receptor repertoire in immunoglobulin G4 associated cholangitis. Hepatology (2013) 57(6):2390-8. doi: $10.1002 /$ hep. 26232

296. Doorenspleet ME, Hubers LM, Culver EL, Maillette de Buy Wenniger LJ, Klarenbeek PL, Chapman RW, et al. Immunoglobulin G4(+) B-cell receptor clones distinguish immunoglobulin $\mathrm{G}$ 4-related disease from primary sclerosing cholangitis and biliary/pancreatic malignancies. Hepatology (2016) 64(2):501-7. doi:10.1002/hep.28568

297. Lohr JM, Faissner R, Koczan D, Bewerunge P, Bassi C, Brors B, et al. Autoantibodies against the exocrine pancreas in autoimmune pancreatitis: gene and protein expression profiling and immunoassays identify pancreatic enzymes as a major target of the inflammatory process. Am J Gastroenterol (2010) 105(9):2060-71. doi:10.1038/ajg.2010.141

298. Asada M, Nishio A, Uchida K, Kido M, Ueno S, Uza N, et al. Identification of a novel autoantibody against pancreatic secretory trypsin inhibitor in patients with autoimmune pancreatitis. Pancreas (2006) 33(1):20-6. doi:10.1097/01. mpa.0000226881.48204.fd 
299. Shiokawa M, Kodama Y, Kuriyama K, Yoshimura K, Tomono T, Morita T, et al. Pathogenicity of IgG in patients with IgG4-related disease. Gut (2016) 65(8):1322-32. doi:10.1136/gutjnl-2015-310336

300. Hubers LM, Vos H, Schuurman AR, Erken R, Oude Elferink RP, Burgering B, et al. Annexin A11 is targeted by IgG4 and IgG1 autoantibodies in IgG4related disease. Gut (2017). doi:10.1136/gutjnl-2017-314548

301. Vincent A, Leite MI, Farrugia ME, Jacob S, Viegas S, Shiraishi H, et al. Myasthenia gravis seronegative for acetylcholine receptor antibodies. Ann N Y Acad Sci (2008) 1132:84-92. doi:10.1196/annals.1405.020

302. Tron F, Gilbert D, Mouquet H, Joly P, Drouot L, Makni S, et al. Genetic factors in pemphigus. J Autoimmun (2005) 24(4):319-28. doi:10.1016/j. jaut.2005.03.006

303. Meyer N, Misery L. Geoepidemiologic considerations of auto-immune pemphigus. Autoimmun Rev (2010) 9(5):A379-82. doi:10.1016/j. autrev.2009.10.009

304. Warren SJ, Lin MS, Giudice GJ, Hoffmann RG, Hans-Filho G, Aoki V, et al. The prevalence of antibodies against desmoglein 1 in endemic pemphigus foliaceus in Brazil. Cooperative Group on Fogo Selvagem Research. N Engl $J$ Med (2000) 343(1):23-30. doi:10.1056/NEJM200007063430104

305. Gomes R, Oliveira F, Teixeira C, Meneses C, Gilmore DC, Elnaiem DE, et al. Immunity to sand fly salivary protein LJM11 modulates host response to vector-transmitted leishmania conferring ulcer-free protection. J Invest Dermatol (2012) 132(12):2735-43. doi:10.1038/jid.2012.205

306. Qian Y, Jeong JS, Maldonado M, Valenzuela JG, Gomes R, Teixeira C, et al. Cutting edge: Brazilian pemphigus foliaceus anti-desmoglein 1 autoantibodies cross-react with sand fly salivary LJM11 antigen. J Immunol (2012) 189(4):1535-9. doi:10.4049/jimmunol.1200842

307. Qian Y, Jeong JS, Ye J, Dang B, Abdeladhim M, Aoki V, et al. Overlapping IgG4 responses to self- and environmental antigens in endemic pemphigus foliaceus. J Immunol (2016) 196(5):2041-50. doi:10.4049/jimmunol.1502233

308. Diaz LA, Prisayanh PS, Dasher DA, Li N, Evangelista F, Aoki V, et al. The IgM anti-desmoglein 1 response distinguishes Brazilian pemphigus foliaceus (fogo selvagem) from other forms of pemphigus. J Invest Dermatol (2008) 128(3):667-75. doi:10.1038/sj.jid.5701121

309. Qian Y, Jeong JS, Abdeladhim M, Valenzuela JG, Aoki V, Hans-Filhio G, et al. IgE anti-LJM11 sand fly salivary antigen may herald the onset of fogo selvagem in endemic Brazilian regions. J Invest Dermatol (2015) 135(3):913-5. doi:10.1038/jid.2014.430

310. Qian Y, Prisayanh P, Andraca E, Qaqish BF, Aoki V, Hans-Filhio G, et al. IgE, IgM, and IgG4 anti-desmoglein 1 autoantibody profile in endemic pemphigus foliaceus (fogo selvagem). J Invest Dermatol (2011) 131(4):985-7. doi:10.1038/jid.2010.403

311. Li N, Aoki V, Hans-Filho G, Rivitti EA, Diaz LA. The role of intramolecular epitope spreading in the pathogenesis of endemic pemphigus foliaceus (fogo selvagem). J Exp Med (2003) 197(11):1501-10. doi:10.1084/jem.20022031

312. Qaqish BF, Prisayanh P, Qian Y, Andraca E, Li N, Aoki V, et al. Development of an IgG4-based predictor of endemic pemphigus foliaceus (fogo selvagem). J Invest Dermatol (2009) 129(1):110-8. doi:10.1038/jid.2008.189

313. Warren SJ, Arteaga LA, Rivitti EA, Aoki V, Hans-Filho G, Qaqish BF, et al. The role of subclass switching in the pathogenesis of endemic pemphigus foliaceus. J Invest Dermatol (2003) 120(1):104-8. doi:10.1046/j.1523-1747.2003.12017.x

314. Kamisawa T, Anjiki H, Egawa N, Kubota N. Allergic manifestations in autoimmune pancreatitis. Eur J Gastroenterol Hepatol (2009) 21(10):1136-9. doi:10.1097/MEG.0b013e3283297417

315. Culver EL, Vermeulen E, Makuch M, van Leeuwen A, Sadler R, Cargill $\mathrm{T}$, et al. Increased IgG4 responses to multiple food and animal antigens indicate a polyclonal expansion and differentiation of pre-existing B cells in IgG4-related disease. Ann Rheum Dis (2015) 74(5):944-7. doi:10.1136/ annrheumdis-2014-206405

316. Culver EL, Sadler R, Bateman AC, Makuch M, Cargill T, Ferry B, et al. Increases in IgE, eosinophils, and mast cells can be used in diagnosis and to predict relapse of IgG4-related disease. Clin Gastroenterol Hepatol (2017) 15(9):1444-52.e6 doi:10.1016/j.cgh.2017.02.007

317. Tian C, Luskin GK, Dischert KM, Higginbotham JN, Shepherd BE, Crowe JE Jr. Immunodominance of the VH1-46 antibody gene segment in the primary repertoire of human rotavirus-specific B cells is reduced in the memory compartment through somatic mutation of nondominant clones. J Immunol (2008) 180(5):3279-88. doi:10.4049/jimmunol.180.5.3279

318. Cho MJ, Ellebrecht CT, Hammers CM, Mukherjee EM, Sapparapu G, Boudreaux CE, et al. Determinants of VH1-46 cross-reactivity to pemphigus vulgaris autoantigen desmoglein 3 and rotavirus antigen VP6. J Immunol (2016) 197(4):1065-73. doi:10.4049/jimmunol.1600567

319. Phongsisay V. The immunobiology of Campylobacter jejuni: innate immunity and autoimmune diseases. Immunobiology (2016) 221(4):535-43. doi:10.1016/j.imbio.2015.12.005

320. Beck LH Jr. The dominant humoral epitope in phospholipase A2 receptor-1: presentation matters when serving up a slice of pi. J Am Soc Nephrol (2015) 26(2):237-9. doi:10.1681/ASN.2014090877

321. Stanescu HC, Arcos-Burgos M, Medlar A, Bockenhauer D, Kottgen A, Dragomirescu L, et al. Risk HLA-DQA1 and PLA(2)R1 alleles in idiopathic membranous nephropathy. N Engl J Med (2011) 364(7):616-26. doi:10.1056/ NEJMoa1009742

322. Jia XY, Cui Z, Yang R, Hu SY, Zhao MH. Antibodies against linear epitopes on the Goodpasture autoantigen and kidney injury. Clin J Am Soc Nephrol (2012) 7(6):926-33. doi:10.2215/CJN.09930911

323. Li JN, Jia X, Wang Y, Xie C, Jiang T, Cui Z, et al. Plasma from patients with anti-glomerular basement membrane disease could recognize microbial peptides. PLoS One (2017) 12(4):e0174553. doi:10.1371/journal.pone.0174553

324. Oka S, Nohgawa M. EB virus reactivation triggers thrombotic thrombocytopenic purpura in a healthy adult. Leuk Res Rep (2017) 8:1-3. doi:10.1016/j. lrr.2017.06.001

325. Kosugi N, Tsurutani Y, Isonishi A, Hori Y, Matsumoto M, Fujimura Y. Influenza A infection triggers thrombotic thrombocytopenic purpura by producing the anti-ADAMTS13 IgG inhibitor. Intern Med (2010) 49(7):689-93. doi:10.2169/internalmedicine.49.2957

326. Rossi FC, Angerami RN, de Paula EV, Orsi FL, Shang D, del Guercio $\mathrm{VM}$, et al. A novel association of acquired ADAMTS13 inhibitor and acute dengue virus infection. Transfusion (2010) 50(1):208-12. doi:10.1111/j.1537-2995.2009.02391.x

327. Kojima Y, Ohashi H, Nakamura T, Nakamura H, Yamamoto H, Miyata Y, et al. Acute thrombotic thrombocytopenic purpura after pneumococcal vaccination. Blood Coagul Fibrinolysis (2014) 25(5):512-4. doi:10.1097/ MBC.0000000000000058

328. Hermann R, Pfeil A, Busch M, Kettner C, Kretzschmar D, Hansch A, et al. [Very severe thrombotic thrombocytopenic purpura (TTP) after H1N1 vaccination]. Med Klin (2010) 105(9):663-8. doi:10.1007/s00063-010-1107-6

329. Brodin-Sartorius A, Guebre-Egziabher F, Fouque D, Cozon G, Villar E, Laville M, et al. Recurrent idiopathic thrombotic thrombocytopenic purpura: a role for vaccination in disease relapse? Am J Kidney Dis (2006) 48(3):e31-4. doi:10.1053/j.ajkd.2006.04.090

330. Perricone C, Ceccarelli F, Nesher G, Borella E, Odeh Q, Conti F, et al. Immune thrombocytopenic purpura (ITP) associated with vaccinations: a review of reported cases. Immunol Res (2014) 60(2-3):226-35. doi:10.1007/ s12026-014-8597-x

331. Hou Z, Abudureheman A, Wang L, Hasim A, Ainiwaer J, Zhang H, et al. Expression, prognosis and functional role of Thsd7a in esophageal squamous cell carcinoma of Kazakh patients, Xinjiang. Oncotarget (2017) 8(36):6053957. doi:10.18632/oncotarget.16966

Conflict of Interest Statement: The author declares that the research was conducted in the absence of any commercial or financial relationships that could be construed as a potential conflict of interest.

Copyright (c) 2018 Koneczny. This is an open-access article distributed under the terms of the Creative Commons Attribution License (CC BY). The use, distribution or reproduction in other forums is permitted, provided the original author(s) and the copyright owner are credited and that the original publication in this journal is cited, in accordance with accepted academic practice. No use, distribution or reproduction is permitted which does not comply with these terms. 